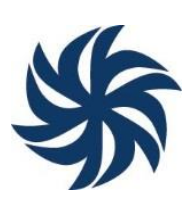

\title{
CORRUPÇÃO E SUCESSO LEGISLATIVO: POSSÍVEIS REFLEXOS DO MENSALÃO E DA LAVA JATO NA CONVERSÃO DE PROPOSIÇÕES EM NORMAS JURÍDICAS
}

\author{
CORRUPTION AND LEGISLATIVE SUCCESS: POSSIBLE REFLEXES OF \\ MENSALÃO E LAVA JATO IN THE CONVERSION OF PROPOSALS IN LEGAL \\ STANDARDS
}

\begin{abstract}
CORRUPCIÓN Y ÉXITO LEGISLATIVO: POSIBLES REFLEJOS DEL MENSALÃO Y LAVA JATO EN LA CONVERSIÓN DE PROPUESTAS EN NORMAS LEGALES
\end{abstract}

\author{
Fabiano Peruzzo Schwartz ${ }^{1}$ \\ Guilherme Marques Veroneze ${ }^{2}$ \\ João Luiz Pereira Marciano ${ }^{3}$
}

\begin{abstract}
Resumo: O presente artigo investiga o fenômeno da corrupção política e se dedica a responder a seguinte questão de pesquisa: qual é o impacto do envolvimento de parlamentar nos esquemas do Mensalão e da Lava Jato (variável independente - VI) na taxa de conversão em norma jurídica de projetos de lei de sua autoria (variável dependente - VD)? O envolvimento, neste estudo, é caracterizado pela condenação de parlamentar no esquema do Mensalão e/ou por indiciamento na Lava Jato. Por hipótese, é razoável supor que vantagens advindas de esquemas de corrupção tendem a favorecer a aprovação de projetos que atendam aos interesses desses esquemas. Para avaliar o efeito de VI em VD, foi utilizada a regressão logística, com adição de outras variáveis como causa concorrente. Os resultados mostram taxa de conversão em norma cerca de 50\% maior para os projetos de parlamentares envolvidos. A análise comparada desses projetos sugere uma conduta parlamentar pautada em interesses setoriais e de concentração de benefícios.
\end{abstract}

Palavras-chave: corrupção; sucesso legislativo; democracia; proposições; criminalização de agentes políticos.

Abstract: This article investigates the phenomenon of political corruption and is dedicated to answering the following research question: what is the impact of the involvement of parliamentarians in the Mensalão and Lava Jato schemes (independent variable - IV) on the conversion rate into legal norm of their own propositions (dependent variable - DV)? Involvement, in this study, is characterized by the condemnation of parliamentarians in the Mensalão scheme and/or by indictment in Lava Jato. Hypothetically, it is reasonable to assume that advantages arising from corruption schemes tend to favor the approval of projects that meet the interests of these schemes. To assess the effect of IV in DV, logistic regression was used, with the addition of other variables as a concurrent cause. Results show conversion rate about $50 \%$ higher for the projects of parliamentarians involved. The comparative analysis of these projects suggests parliamentary conduct based on sectoral interests and benefit concentration.

Keywords: corruption; legislative success; democracy; criminalization of political agents

\footnotetext{
${ }^{1}$ Doutor em Engenharia de Sistemas Eletrônicos e de Automação e Mestre em Ciência da Computação, ambos pela Universidade de Brasília. Diretor da Coordenação de Pós-Graduação da Câmara dos Deputados e professor permanente do Mestrado Profissional em Poder Legislativo. Coordena o grupo de pesquisa e extensão "Ciência de Dados Aplicada ao Estudo do Poder Legislativo: abordagem computacional e métodos de análise", cadastrado no Diretório dos Grupos de Pesquisa do CNPq. Orcid Id: https://orcid.org/0000-0003-1727-9346. E-mail: fabiano.schwartz@ camara.leg.br.

${ }^{2}$ Mestre em Poder Legislativo pelo Cefor - Centro de Formação, Treinamento e Aperfeiçoamento da Câmara dos Deputados. Graduado em Administração pela Universidade de Brasília. Servidor do Senado Federal, tem experiência nas áreas de Direito Administrativo e Processo Legislativo. Orcid Id: https://orcid.org/0000-0003-0112-442X. E-mail: veroneze@ senado.gov.br.

${ }^{3}$ Doutor em Ciência da Informação e Mestre em Ciência da Computação, ambos pela Universidade de Brasília. Secretário de Controle Interno da Câmara dos Deputados e professor permanente do Mestrado Profissional em Poder Legislativo. Possui as certificações CISA, CGEIT, CRISC e CISM. Orcid Id: https://orcid.org/0000-0002-2436-9166. E-mail: joao.marciano@ camara.leg.br.
} 
Resumen: Este artículo investiga el fenómeno de la corrupción política y se dedica a responder la siguiente pregunta de investigación: ¿cuál es el impacto de la participación de los parlamentarios en los esquemas de Mensalão y Lava Jato (variable independiente - VI) en la tasa de conversión en normas legales para proposiciones de su autoría (variable dependiente - VD)? La participación, en este estudio, se caracteriza por la condena de los parlamentarios en el esquema de Mensalão y/o por la acusación en Lava Jato. Hipotéticamente, es razonable suponer que las ventajas derivadas de los esquemas de corrupción tienden a favorecer la aprobación de proyectos que satisfacen los intereses de estos esquemas. Para evaluar el efecto de VI en VD, se utilizó la regresión logística, con la adición de otras variables como causa concurrente. Los resultados muestran una tasa de conversión aproximadamente 50\% más alta para los proyectos de parlamentarios involucrados. El análisis comparativo de estos proyectos sugiere una conducta parlamentaria basada en intereses sectoriales y concentración de beneficios.

Palabras clave: corrupción; éxito legislativo; democracia; criminalización de agentes políticos

\section{Introdução}

Notícias sobre corrupção veiculadas pela mídia nos últimos anos têm mencionado, com certa frequência, o envolvimento de agentes públicos e de atores políticos do cenário brasileiro em ações ilícitas de toda ordem, com amplo destaque para os esquemas do Mensalão e da Lava Jato (FOLHA DE SÃO PAULO, 2019; REVISTA VEJA, 2020; THE ECONOMIST, 2019; R7, 2017). Valores vultosos, com soma na casa de bilhões de reais, são desviados ou pagos a grupos de pessoas no exercício de cargos públicos e eletivos, alcançando parlamentares e governantes.

No sentido de coibir tais atos, diplomas legais como a Lei de Responsabilidade Fiscal (BRASIL, 2000), a Lei de Acesso à Informação (BRASIL, 2011) e a Lei de Combate à Corrupção (BRASIL, 2013b), entre outros, podem ser citados como exemplos que visam ao aumento do controle sobre gastos, da transparência e da accountability do aparelho público por parte da sociedade. Contudo, a maneira e intensidade como a corrupção é percebida pela sociedade vai além do caráter jurídico ou normativo.

O processo eleitoral, por pouco mais de duas décadas e em período anterior ao ano de 2015, permitiu que parte significativa dos recursos recebidos pelos candidatos viesse por meio de doações de empresas, atingindo a ordem de $45 \%$ para candidatos a deputado federal nas eleições ocorridas entre 2002 e 2014 (SPECK; MARCIANO, 2015). Os valores de gastos de campanha declarados ao Tribunal Superior Eleitoral (TSE) nas eleições de 2014 foram da ordem de R\$5,1 bilhões de reais, sendo $\mathrm{R} \$ 1,1$ bilhão declarados pelos candidatos a deputados federais e pouco mais de $\mathrm{R} \$ 280$ milhões declarados pelos candidatos ao Senado Federal.

As motivações pelas quais empresas contribuem com campanhas políticas são amplamente discutidas na literatura (MCMENAMIN, 2012; PINTODUSCHINSKY, 2002; PORTUGAL, 2006; RUBIO, 2005; SANTOS, 2009). O ponto de interesse, aqui, é o momento em que essas contribuições deixam a legalidade e resvalam para a obscuridade, passando a constituir focos de corrupção e inserindo assimetrias competitivas no processo eleitoral, de início, e no comportamento político dos agentes envolvidos, em etapas posteriores, durante o exercício de seus mandatos. 
Segundo levantamento efetuado, considerando cerca de 123 mil projetos protocolados desde 1943 por parlamentares da Câmara e Senado brasileiros, menos de 1\% desses projetos foram convertidos em norma jurídica, contra um percentual de $4 \%$ das propostas no Congresso dos Estados Unidos que são convertidas em lei (JOTA, 2019). Achados dessa natureza alertam para novas questões que precisam considerar o poder de influência do agente político. É sabido que o arranjo institucional do parlamento confere mais poder a certos parlamentares que a outros. Notadamente, membros das Mesas Diretoras das Casas do Congresso Nacional e das Assembleias Legislativas, líderes partidários e presidentes de Comissões têm maior capacidade formal de influenciar os trabalhos legislativos (FIGUEIREDO; LIMONGI, 2001; LEMOS, 2008; SANTOS; MEDEIROS; SANTOS, 2008; RICCI; LEMOS, 2004; SANTOS, 2000). Contudo, existiriam outros fatores capazes de conferir ao parlamentar equivalente poder de influência?

Nesse sentido, o presente artigo investiga o fenômeno da corrupção política como possível fator explicativo do sucesso legislativo, aqui tratado pontualmente como a capacidade de um parlamentar converter em norma jurídica projetos de lei de sua autoria, e se dedica a responder a seguinte questão de pesquisa: qual é o impacto do envolvimento de parlamentar nos esquemas do Mensalão e da Lava Jato (variável independente - VI) na taxa de conversão em norma jurídica de projetos de lei de sua autoria (variável dependente - VD)? O "envolvimento", neste estudo, é caracterizado pela condenação de parlamentar no esquema do Mensalão e/ou por indiciamento na Lava Jato. Por hipótese, é razoável supor que vantagens advindas de esquemas de corrupção tendem a favorecer a aprovação de projetos que atendam aos interesses desses esquemas. Então, adicionalmente, o estudo busca esclarecimentos sobre se essas normas distribuíram benefícios a certos setores econômicos identificáveis ou a regiões geográficas específicas que caracterizem interesse próprio desses parlamentares na orientação de políticas públicas.

Este trabalho inova ao apresentar uma abordagem quantitativa do impacto do Mensalão e da Lava Jato na atividade política brasileira. Pesquisas sobre esse tema, em geral, abordam aspectos jurídicos e problemas do sistema político-eleitoral brasileiro (MATOS FILHO, 2017; LIMA, 2018; FIGUEIREDO, 2018). É importante ressaltar que a abordagem estatística deste estudo não esgota os pressupostos que estabelecem a presença de uma relação causal robusta (PARANHOS et al, 2013). Ao contrário, é sabido que em temas políticos, em especial o do sucesso legislativo, há um conjunto de fatores que devem ser levados em conta e que são aqui abstraídos ${ }^{4}$, por razão de indisponibilidade dos respectivos dados em uma forma estruturada. Contudo, ainda que com escopo reducionista, a pesquisa revela forte associação dos eventos do Mensalão e da Lava Jato com a aprovação de projetos no mesmo período, condição necessária

\footnotetext{
${ }^{4}$ A aprovação de projetos é apenas um dos elementos do sucesso legislativo, mas não o único. A aprovação de emendas é igualmente relevante, além da trajetória/carreira política, o pertencimento a famílias tradicionais da política ou o apoio delas, a conexão com grupos empresariais, grandes corporações, grupos de pressão ou movimentos sociais de grande expressão política, a ocupação de cargos ao longo da carreira e no parlamento (como liderança partidária, presidência de comissão e relatoria de projetos).
} 
para futuros estudos que se dediquem a investigar os demais requisitos necessários às relações de causalidade desses fenômenos.

\section{A corrupção e seus efeitos}

Para Huntington (2006, p. 59), pode-se entender a corrupção nos setores público e político como o comportamento de agentes públicos e políticos que se desviam das normas aceitas para atender a fins privados. Esta é a acepção seguida neste texto. O mesmo autor (HUNTINGTON, 2006, p. 5) afirma que a corrupção possui três efeitos altamente danosos para a democracia uma vez que: aumenta a frustração social na medida em que diminui o desenvolvimento econômico; reduz a participação política, pois diminui as oportunidades de mobilidade econômica ao atuar contra o progresso econômico e social; aumenta a instabilidade política, visto que enfraquece as instituições.

A forma como a sociedade percebe o fenômeno corrupção tem pautado a agenda de diversos pesquisadores. Segundo Kubbe (2013, p. 43) é praticamente impossível mensurar diretamente o fenômeno uma vez que cada fato apurado goza de características próprias cuja aferição, post factum, não se configura em procedimento evidente e, portanto, não se molda facilmente a análises de cunho comparativo. Para Feres Júnior e Sassara (2016), é na mídia que a corrupção se torna escândalo, e é por meio do agendamento e do enquadramento feitos pelos meios de comunicação que um conjunto de práticas e fatos é tornado público e formatado de maneira a constituir um produto, com narrativas próprias, personagens principais e um nome próprio ("Mensalão", "Lava Jato", etc). Logo, a investigação acadêmico-científica do tema requer esforço adicional na identificação de fatores explicativos dos fenômenos observados.

Speck (2000) salienta diferentes abordagens de se avaliar a percepção de corrupção, tais como pesquisas de opinião, a quantificação de penas ou sanções aplicadas a agentes públicos e a existência e eficácia de programas públicos de combate à corrupção. Uma das conclusões é de que a corrupção é mais aceita quando não é vista como um comportamento errôneo, ou quando é disseminada pelos grupos sociais em que o indivíduo se insere (TAVITS, 2010). Não se pode deixar de registrar que uma das formas de se prevenir os cidadãos contra a prática e os efeitos da corrupção é, exatamente, a educação, tanto como forma de promover a honestidade e a confiança mútua, como forma de promover o aumento da riqueza e da igualdade, ambas associadas a baixos índices de corrupção (USLANER; ROTHSTEIN, 2016, p. 228).

Para Ribeiro (2000), a corrupção se limita à questão do trânsito ilegal de dinheiro, geralmente tendo a malversação de fundos públicos como fim. $\mathrm{Na}$ linha desse entendimento, Caldas, Costa e Pagliarussi (2016) verificaram significativa concentração de ações de corrupção nos gastos destinados à educação e à saúde, no Brasil. Mauro (1998) e Gupta, de Mello e Sharan (2001) concluíram que a corrupção resulta em distorções orçamentárias, visto que o sigilo requerido pelas transações corruptas pode levar ao desvio de gastos governamentais em áreas 
prioritárias, como saúde e educação, para áreas não usuais, como defesa e obras de infraestrutura, nas quais é mais fácil apropriar-se do recurso público. Sodré e Alves (2010), ao investigarem a relação entre emendas parlamentares ao orçamento e corrupção no âmbito municipal, observaram que o aumento da corrupção parece estar mais relacionado com o fato de um município receber alguma emenda do que com o valor total das emendas recebidas.

Em termos objetivos, dada a própria fluidez das ações executadas pelos agentes envolvidos, existe enorme dificuldade em se avaliar o volume dos recursos econômicos, humanos e tecnológicos movimentados em decorrência da corrupção. No Brasil, a título de exemplo, um dos procuradores do Ministério Público responsáveis pela condução da operação Lava Jato estima que, anualmente, cerca de $\mathrm{R} \$ 200$ bilhões seriam desviados em todo o país (CARVALHO, 2016). Isso equivale a cerca de $3,2 \%$ do Produto Interno Bruto nacional, levando-se em conta os números divulgados pelo Banco Central do Brasil no primeiro trimestre de 2017 (BANCO CENTRAL DO BRASIL, 2017).

Nota-se, portanto, que o controle público, tanto por parte do Estado quanto da sociedade, assume papel cada vez mais preponderante sobre os mecanismos de combate à corrupção. Não por acaso, discute-se com crescente interesse o aumento da transparência do Estado, ao mesmo tempo em que se busca proporcionar à sociedade formas de monitoramento e controle sobre a aplicação de recursos públicos (KNIRSCH, 2011) e as ações da corrupção (BERTOT; JAEGER; GRIMES, 2010).

No entanto, uma avaliação das instituições brasileiras destinadas ao combate da corrupção aponta que essas passam por diversas dificuldades, como a baixa oferta e mensuração de accountability vertical (POWER; TAYLOR, 2011), interrupção de geração de oportunidades e de ações coletivas (PERSSON; ROTHSTEIN; TEORELL, 2013), comprometimento da resposta do aparelho público a suas missões institucionais (TORRES, 2004), além de carecerem de maior independência quanto a pressões políticas, fenômeno que se repete pelo globo (JOHNSTON, 2000; ROTHSTEIN; TEORELL, 2008). A própria avaliação dos agentes políticos, em comparação com outras categorias, mostra que não são apenas brasileiros que veem os partidos e os políticos entre as instituições e atores mais corruptos, como mostra a Tabela 1. 
Tabela 1- Percepção de corrupção por categoria: percentual de respondentes que avaliaa categoria como "corrupta" ou "extremamente corrupta".

\begin{tabular}{lccc}
\hline Categoria & Brasil & Argentina & Chile \\
\hline Partidos políticos & 81 & 78 & 76 \\
Parlamentares & 72 & 72 & 68 \\
Polícia & 70 & 70 & 53 \\
Profissionais e servidores da saúde & 55 & 26 & 51 \\
Poder Judiciário & 50 & 65 & 67 \\
Autoridades e servidores públicos & 46 & 77 & 58 \\
Mídia & 38 & 44 & 48 \\
ONGs & 35 & 22 & 32 \\
Empresariado & 35 & 49 & 65 \\
Sistema educacional & 33 & 23 & 60 \\
Grupos religiosos & 31 & 34 & 45 \\
Militares & 30 & 32 & 36 \\
\hline
\end{tabular}

Fonte: Transparency International (2013). N = 2002, 1001, 1000.

No Brasil, em especial, o percentual elevado da percepção de corrupção associado a partidos políticos e parlamentares advém de dados contemporâneos aos eventos sob estudo neste artigo, e é coerente com fatos ocorridos nos anos recentes, particularmente durante o processo de redemocratização, em que o país tem se deparado com uma sucessão de eventos relacionados à corrupção em larga escala, os denominados "esquemas", justamente envolvendo agentes políticos. O Quadro 1 apresenta uma relação desses eventos no período 1989-2014.

Quadro 1 - Alguns dos principais casos de corrupção no Brasil, no período 1989-2014, envolvendo agentes políticos no exercício de mandato.

\begin{tabular}{|c|c|c|c|c|}
\hline Caso & Período & Abrangência & $\begin{array}{c}\text { Estimativa } \\
\text { nominal }\end{array}$ & Descrição \\
\hline $\begin{array}{l}\text { Anões do } \\
\text { Orçamento }\end{array}$ & $1989-1992$ & $\begin{array}{l}\text { Congresso } \\
\text { Nacional }\end{array}$ & $\mathrm{R} \$ 800$ milhões & $\begin{array}{l}\text { Sete deputados (os chamados } \\
\text { "anões") da Comissão Mista de } \\
\text { Orçamentos submetiam emendas } \\
\text { destinando valores a entidades } \\
\text { filantrópicas ligadas a parentes, } \\
\text { além de cobrar de empreiteiras } \\
\text { para destinar valores a obras que } \\
\text { eram superfaturadas. }\end{array}$ \\
\hline $\begin{array}{l}\text { Collorgate ou } \\
\text { "esquema" PC }\end{array}$ & 1992 & $\begin{array}{l}\text { Presidência da } \\
\text { República }\end{array}$ & US\$10milhões & $\begin{array}{l}\text { Pedro Collor, irmão do presidente, } \\
\text { divulga dossiê em que o acusa de } \\
\text { fraudes na declaração de gastos de } \\
\text { campanha e de manter contas } \\
\text { ocultas. Depois de vários } \\
\text { desdobramentos, Fernando Collor } \\
\text { foi deposto em votação na Câmara } \\
\text { dos Deputados. }\end{array}$ \\
\hline $\begin{array}{l}\text { TRT de São } \\
\text { Paulo }\end{array}$ & 1992-1999 & $\begin{array}{l}\text { Tribunal } \\
\text { Regional do } \\
\text { Trabalho do } \\
\text { Estado de São } \\
\text { Paulo }\end{array}$ & $\mathrm{R} \$ 923$ milhões & $\begin{array}{l}\text { Apesar de ter perdido a licitação } \\
\text { para a construção do edifício do } \\
\text { Fórum do TRT-SP, o Grupo OK, } \\
\text { do senador Luis Estêvão, recebia } \\
\text { repasses vultosos por ordem do } \\
\text { presidente do TRT, Nicolau dos } \\
\text { Santos Neto, que também recebia } \\
\text { "comissão". }\end{array}$ \\
\hline Mensalão & 2005 & Câmara dos & $\mathrm{R} \$ 55$ milhões & Denunciados pelo então deputado \\
\hline
\end{tabular}




\begin{tabular}{|c|c|c|c|c|}
\hline & & Deputados & & $\begin{array}{l}\text { Roberto Jefferson (PTB), políticos } \\
\text { recebiam“mensalidades" para } \\
\text { apoiar o PT. }\end{array}$ \\
\hline Sanguessugas & 2006 & $\begin{array}{l}\text { Prefeituras } \\
\text { municipais e } \\
\text { Congresso } \\
\text { Nacional }\end{array}$ & $\mathrm{R} \$ 140$ milhões & $\begin{array}{l}\text { Empresários pagavam a } \\
\text { parlamentares para que } \\
\text { submetessem e aprovassem } \\
\text { emendas para compra } \\
\text { superfaturada de materiais } \\
\text { hospitalares e ambulâncias. }\end{array}$ \\
\hline $\begin{array}{l}\text { Operação } \\
\text { Navalha }\end{array}$ & 2007 & $\begin{array}{l}\text { Prefeituras } \\
\text { municipais, } \\
\text { Câmara dos } \\
\text { Deputados e } \\
\text { Ministério de } \\
\text { Minas e Energia }\end{array}$ & $\mathrm{R} \$ 610$ milhões & $\begin{array}{l}\text { Empresários pagavam a servidores } \\
\text { públicos para direcionar licitações }\end{array}$ \\
\hline $\begin{array}{l}\text { Máfia dos } \\
\text { Transportes }\end{array}$ & 2011 & $\begin{array}{l}\text { Departamento } \\
\text { Nacional de } \\
\text { Infraestrutura de } \\
\text { Transportes } \\
\text { (Dnit) }\end{array}$ & $\mathrm{R} \$ 23$ milhões & $\begin{array}{l}\text { Luiz Antônio Pagot (PR), que } \\
\text { chefiava o órgão, e membros do } \\
\text { partido cobravam "comissão" de } \\
\text { empresários que desejassem } \\
\text { participar de licitações para } \\
\text { grandes obras. }\end{array}$ \\
\hline $\begin{array}{l}\text { Operação Lava } \\
\text { Jato }\end{array}$ & 2014- & $\begin{array}{l}\text { Petrobrás, } \\
\text { Congresso } \\
\text { Nacional, } \\
\text { Presidência da } \\
\text { República, } \\
\text { governos } \\
\text { estaduais }\end{array}$ & $\mathrm{R} \$ 42,8$ bilhões & $\begin{array}{l}\text { O nome se refere a ações da } \\
\text { Polícia Federal e do Ministério } \\
\text { Público com vistas a elucidar } \\
\text { "esquemas" de corrupção pagos } \\
\text { com verbas desviadas em grande } \\
\text { parte da estatal. Mais de uma } \\
\text { centena de políticos de diversos } \\
\text { partidos foram denunciados ou } \\
\text { estão sendo investigados, pelo } \\
\text { Ministério Público, que pediu } \\
\text { autorização ao Supremo Tribunal } \\
\text { Federal ("lista do Teori" e"lista do } \\
\text { Fachin".) }\end{array}$ \\
\hline
\end{tabular}

Fonte: Elaboração própria a partir de Praça (2011), Power e Taylor (2011), Barbosa e Maia (2017), Pereira e Sardinha (2017), Folha de São Paulo (1995), Araujo, Costa e Fittipaldi (2016).

Parece ser consensual a ideia de que a crise enfrentada pelo Brasil no cenário políticoeconômico decorre, em grande parte, de atos de corrupção como os apresentados no Quadro 1, em especial os revelados na operação Lava Jato e no escândalo do Mensalão, que acarretam, entre outras perdas, clara redução de oportunidades e de oferta adequada de serviços públicos.

Abordar-se o tema da corrupção sob a égide da política requer que se observe os seus impactos sobre os efeitos da capacidade de as instituições proverem os bens e serviços que delas são esperados. Exemplo da redução dessa capacidade é mostrado por Ferraz, Finan e Moreira (2012), que analisam as consequências do desvio de verbas destinadas à educação pública infantil sobre o desempenho de alunos brasileiros em avaliações como o PISA (Programme for International Student Assessment; em tradução livre, Programa Internacional de Avaliação de Estudantes), onde estudantes do país pontuam entre os piores índices globais.

Avritzer e Filgueiras (2011) alinham como dimensões da corrupção no Brasil a organização do sistema político, a organização do Estado e a organização das formas e controle, para além de uma perspectiva moralista, que comumente cai como um véu sobre análises menos 
criteriosas do fenômeno. Os autores concordam que o combate à corrupção deve se centralizar no eixo dos controles: democráticos, vistos sob os aspectos administrativo-burocrático, com a criação e fortalecimento de agências especializadas no combate à corrupção; judicial, reforçando o controle do estamento jurídico sobre a administração pública; e não estatal, exercido pela sociedade e focado no interesse público (AVRITZER; FILGUEIRAS, 2011, p. 16).

Em 2013, a Controladoria-Geral da União (CGU) baixou a Portaria n. 1309, de 15 de julho, que aprova a realização do Programa de Fortalecimento da Prevenção e Combate à Corrupção na Gestão Pública Brasileira (Proprevine), contando com financiamento parcial do Banco Interamericano de Desenvolvimento (BID) (BRASIL, 2013a). Em agosto daquele ano foi promulgada a Lei de Combate à Corrupção (BRASIL, 2013b), que dispõe sobre a responsabilização administrativa e civil de pessoas jurídicas pela prática de atos contra a administração pública, nacional ou estrangeira. Essa lei (Lei n. 12.846/2013, art. 16) permite que a autoridade máxima de cada órgão ou entidade pública possa celebrar acordos de leniência com as pessoas jurídicas responsáveis por atos lesivos nela previstos, a fim de facilitar a identificação de outros envolvidos e a obtenção de informações ou documentos que comprovem os fatos apurados. Os acordos de leniência são frequentemente comparados ao dispositivo da delação premiada, previsto para pessoas físicas e instituído pela Lei n. 8072 de 1990 (BRASIL, 1990).

Nessa conjuntura repousam os principais desafios das instituições públicas, com particular ênfase para o Poder Legislativo, no resgate da credibilidade institucional e no combate à corrupção (POLVEIRO-JÚNIOR, 2006), uma vez que já foi mostrado que as urnas não são efetivas na punição de agentes identificados com práticas corruptas (SOUSA; MORICONI, 2013). Nesse sentido, o presente estudo pretende contribuir para a identificação de possível efeito da corrupção no sucesso legislativo de uma proposta de lei.

\section{Metodologia}

A coleta de dados se deu por leitura direta dos projetos de lei a partir do portal de Transparência da Câmara dos Deputados (CÂMARA DOS DEPUTADOS, 2019). Seguindo práticas da reprodutibilidade de pesquisa, que vêm ganhando caráter mandatório perante a comunidade científica mundial (MCNUTT, 2014), o passo-a-passo da construção do modelo estatístico, o conjunto de dados utilizados e os códigos de programação em linguagem $\mathrm{R}$ (ambiente RStudio v. 1.2.5033) escritos para a obtenção dos resultados estão disponíveis em repositório público (CEFOR, 2019) $)^{5}$.

\footnotetext{
${ }^{5}$ https://github.com/Cefor/corrupcao
} 
Para a construção do modelo estatístico apresentado nesta seção, foram obtidos dados de projetos de lei (PL), projetos de lei complementar (PLP) e projetos de emenda constitucional (PEC) submetidos tanto à Câmara dos Deputados quanto ao Senado Federal no período de 2003 a 2015, ou seja, os dois períodos do governo Lula e o primeiro mandato de Dilma Roussef. Dito

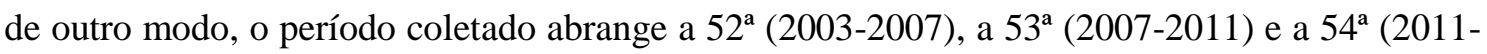
2015) legislaturas, momentos em que tanto o Mensalão quanto a Operação Lava Jato estavam em seus estágios mais agudos. Desse levantamento resultaram 23.635 projetos.

Em seguida, foram excluídas as proposições consideradas de baixo impacto legislativo, ou seja, destinadas a fins tais como denominar ou alterar a denominação de locais ou obras públicas, instituir datas comemorativas e homenagear pessoas ou instituições, bem como aquelas cujo nome encontrava-se em branco, restando 23.287 projetos, dentre os quais 228 foram convertidos em normas jurídicas (cerca de $1 \%$ ).

Para o presente estudo, foi criado um indicador de corrupção, denominado IND_CORRUPCAO, cuja valoração é relacionada ao evento do Mensalão, com base na Ação Penal 470 Minas Gerais (STF, 2012), e à Operação Lava Jato, a partir das assim chamadas "lista do Ministro Teori Zavascki" (LEÃO, 2016) e "lista do Ministro Edson Fachin" (BARBOSA; MAIA, 2017), esta última compreendendo oito ministros de Estado, 24 senadores, 39 deputados federais e três governadores, todos no exercício de mandato.

Após denúncias feitas ao Ministério Público e à Justiça, incluindo dezenas de executivos das empresas Odebrecht e Petrobrás, a Procuradoria-Geral da República (PGR) remeteu ao Supremo Tribunal Federal (STF), que é a instância capaz de autorizar a abertura de inquérito contra detentores de mandato no Senado Federal e na Câmara dos Deputados (BRASIL, 2004, art. $53, \S 1^{\circ}$ ), os pedidos para tais procedimentos. Com as autorizações expedidas por aquela Corte, políticos que foram citados nas delações tornaram-se indiciados, dando-se início a diferentes inquéritos, fase inicial para apuração de informações. Nos casos em que as denúncias foram formalizadas, os indiciados passaram à situação de réus e, após julgamento, condenados ou inocentados.

Obedecendo-se a essa lógica, o indicador de corrupção foi marcado como "verdadeiro" (ou 1) para os políticos cujos nomes apareceram na condição de indiciado, no caso da Operação Lava Jato, ou na condição de condenado, no caso do Mensalão, e como "falso" (ou 0) para os demais. Importante ressaltar que a simples citação de parlamentar nas listas não caracterizava o envolvimento em esquema de corrupção, o que foi considerado somente para as condições indiciado e condenado descritas.

Dados de coalizão disponíveis no Banco de Dados Legislativos do CEBRAP (Centro Brasileiro de Análise e Planejamento) - (CEBRAP, 2019) foram adicionados aos registros das proposições, considerando-se o ano da proposição e o partido do respectivo autor à época. 
Construída a base de dados, procedeu-se à regressão logística, utilizando-se a função glm (general linear model) da linguagem R, tomando-se como variável dependente (VD) o indicador booleano de conversão em norma jurídica, denominado IND_CONVERSAO_LEI (1 - para projetos convertidos; 0 - para projetos não convertidos), e como variável independente (VI) o indicador de corrupção (IND_CORRUPCAO), testando-se como causas concorrentes as demais variáveis do Quadro 2. Neste estudo foram consideradas apenas as variáveis disponíveis nos portais de dados abertos da Câmara dos Deputados e do CEBRAP, à exceção da variável IND_CORRUPCAO, cuja construção já foi esclarecida. A escolha da regressão logística se deveu ao fato de a variável dependente ser dicotômica.

Quadro 2 - Variáveis de análise utilizadas nos modelos de regressão logística.

\begin{tabular}{|c|c|}
\hline Variável & Descrição \\
\hline IND_CONVERSAO_LEI & $\begin{array}{l}\text { Variável dependente, indica se um projeto de lei foi convertido em } \\
\text { norma jurídica ( } 1 \text { - convertido; } 0 \text { - não convertido). }\end{array}$ \\
\hline IND_CORRUPCAO & $\begin{array}{l}\text { Variável independente, categórica, indica o envolvimento de } \\
\text { parlamentar nos esquemas do Mensalão e/ou da Lava Jato ( } 1- \\
\text { envolvido; } 0 \text { - não envolvido). }\end{array}$ \\
\hline SIG_TIPO_PROPOSICAO & $\begin{array}{l}\text { Variável de controle, categórica, indica o tipo da proposição: PL } \\
\text { (Projeto de Lei); PLP (Projeto de Lei Complementar); PEC (Proposta } \\
\text { de Emenda à Constituição). }\end{array}$ \\
\hline NUM_LEGISLATURA & $\begin{array}{l}\text { Variável de controle, categórica, correspondente ao número da } \\
\text { legislatura em que foi apresentada a proposição: } 52,53 \text { ou } 54 \text {. }\end{array}$ \\
\hline COALIZAO & $\begin{array}{l}\text { Variável de controle, categórica, contém o nome da coalizão à qual o } \\
\text { partido do autor pertencia à época da proposta. }\end{array}$ \\
\hline AREA_TEMATICA & $\begin{array}{l}\text { Variável de controle, categórica, contém a área temática da } \\
\text { proposição. }\end{array}$ \\
\hline
\end{tabular}

Fonte: Elaboração própria. Variáveis: IND_CORRUPCAO baseada em STF (2012), Leão (2016) e Barbosa e Maia (2017); COALIZAO extraída de CEBRAP (2019); demais, extraídas de CÂMARA DOS DEPUTADOS (2019).

A seleção do modelo estatístico foi orientada pela técnica iterativa de comparação de modelos aninhados, partindo-se da variável explicativa principal IND_CORRUPCAO, adicionando-se nova variável de controle a cada iteração e verificando-se os indicadores de qualidade do modelo. Os modelos foram avaliados pelo critério da estatística do desvio (deviance statistics) (HILBE, 2009, p. 246), que observa dois requisitos: (1) o modelo proposto deve ser estatisticamente diferente do modelo nulo (aquele somente com o intercepto); (2) o modelo proposto não deve ser estatisticamente diferente do modelo saturado (aquele que tem um coeficiente para cada observação do conjunto de dados). A estatística do desvio é testada por funções qui-quadrado.

Após a aferição dos resultados quantitativos, efetuou-se a análise qualitativa comparada, sob o enfoque neoinstitucionalista, dos projetos de lei convertidos em norma e identificados com o indicador de corrupção, combinando-se as abordagens metodológicas dos estudos de AmorimNeto e Santos (2003) e Lemos (2001). Escolheu-se a corrente neoinstitucionalista por ser menos voltada à análise de normas constitucionais e regimentais, e mais focada nos fenômenos reais sob análise (resultados das deliberações, comportamento dos agentes etc), aferíveis de forma objetiva, 
buscando explicar como os atores políticos agem, quais as suas motivações e, no caso em tela, quais os ganhos potenciais obtidos no processo, em termos de benefícios distribuídos via legislação aprovada.

Foi verificado, também, se os autores desses projetos ocupavam posição de destaque no ano em que o respectivo projeto foi convertido em norma jurídica, como cargo na Mesa Diretora da Câmara dos Deputados, líder de partido ou presidente de comissão, com vistas a se avaliar a influência dessa posição no sucesso legislativo. Essa informação tem caráter complementar, foi obtida por meio de análise documental das biografias de parlamentares e somente foi adicionada na fase final da análise por se tratar de um universo de 30 projetos. Tal levantamento não seria viável para as mais de vinte mil proposições extraídas dos portais de dados abertos.

\section{Resultados e análise comparada}

Os resultados encontrados para a regressão logística do modelo básico, considerando apenas VD e VI, são apresentados no Quadro 3.

Quadro 3 - Modelo 1: IND_CONVERSAO_LEI $=\beta_{0}+\beta_{1} I N D \_C O R R U P C A O$

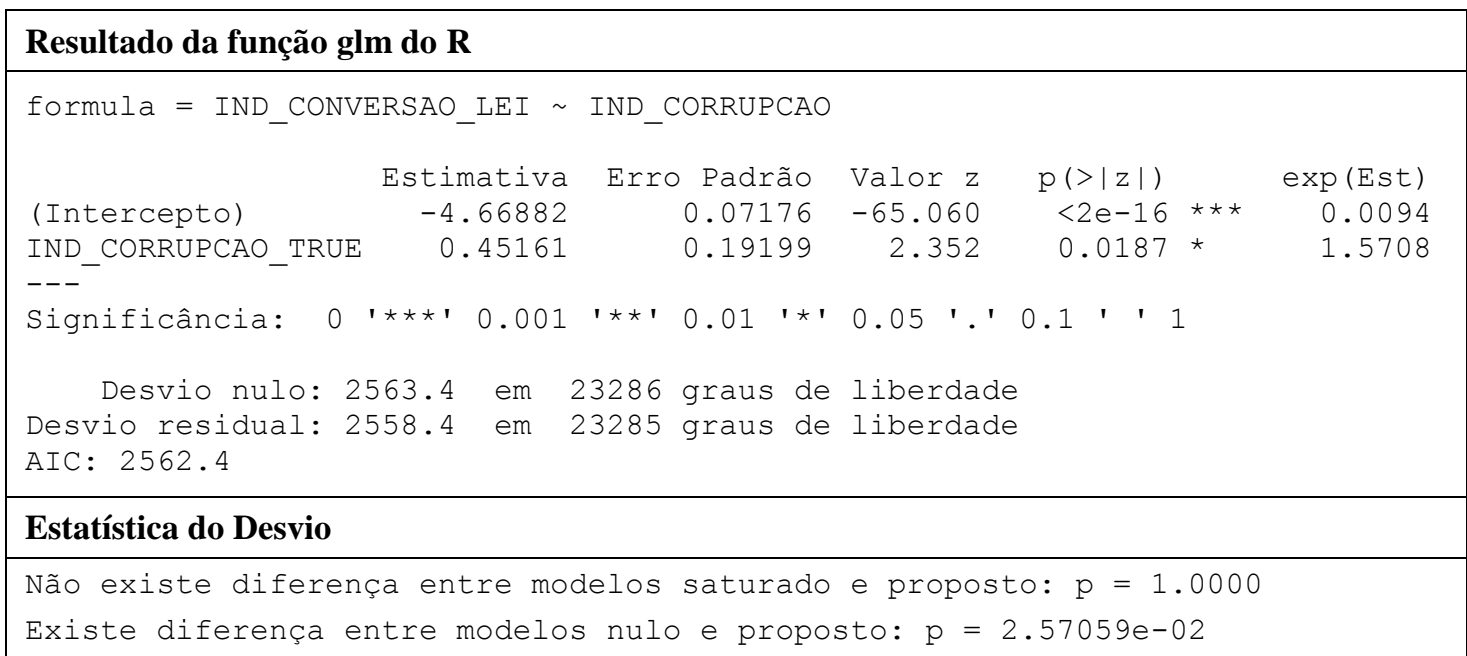

Fonte: Elaboração própria. A coluna exp(Est) foi incluída pelos autores e representa a função exponencial $e$, inversa da função logaritmo neperiano $l n$, para cada coeficiente estimado (coluna Estimativa).

Observa-se, do Quadro 3, que os coeficientes da regressão logística são significativos (p $<0,05)$, o que leva às seguintes interpretações:

1) $\beta_{0}$ (intercepto) corresponde à chance, no domínio logarítmico, de um parlamentar converter um projeto de lei em norma jurídica quando IND_CORRUPCAO é falso; logo, no domínio real $\left(e^{\beta_{0}}\right)$, a chance é estimada em $0,94 \%$; em outras palavras, menos de $1 \%$ dos projetos apresentados por parlamentares são convertidos em norma jurídica, o que é coerente com o levantamento realizado por JOTA (2019).

2) $\beta_{1}$ (IND_CORRUPCAO_TRUE) corresponde à razão das chances no domínio logarítmico, e compara a chance de sucesso legislativo quando IND_CORRUPCAO 
é verdadeiro com a chance de sucesso legislativo quando IND_CORRUPCAO é falso; logo, no domínio real $\left(e^{\beta_{I}}\right)$, a chance de parlamentar possivelmente envolvido em corrupção converter um projeto de lei em norma jurídica é 57,08\% maior que a de parlamentar não envolvido.

Verificada a significância de IND_CORRUPCAO como fator explicativo da conversão de projetos em lei, novas variáveis foram testadas como causa concorrente. O Quadro 4 apresenta o resultado da adição de cada nova variável de controle ao modelo básico. Observa-se que a adição de SIG_TIPO_PROPOSICAO e AREA_TEMATICA não são significativas. O primeiro caso se justifica pelo fato de haver extrema predominância de PLs (87,7\%) em relação aos PLPs $(5,9 \%)$ e PECs $(6,4 \%)$. O segundo, pelo fato de as áreas temáticas não contarem com uma estrutura apropriada na base de dados abertos, onde se pode identificar sobreposição e repetição de temas com descrições distintas, totalizando 512 áreas, o que não corresponde à realidade.

Quadro 4 - Adição de variáveis de controle ao modelo básico.

\begin{tabular}{|c|c|c|c|c|c|}
\hline \multicolumn{6}{|c|}{ Resultado da função add1 do $R$} \\
\hline \multicolumn{6}{|c|}{$\begin{array}{l}\text { ModelO: } \\
\text { IND_CONVERSAO_LEI } \sim \text { IND_CORRUPCAO }\end{array}$} \\
\hline <modelo original> & $\mathrm{Gl}$ & $\begin{array}{l}\text { Desvio } \\
2528.4\end{array}$ & $\begin{array}{c}\text { AIC } \\
2562.4\end{array}$ & LRT & $\mathrm{p}(>\mathrm{Ch} i)$ \\
\hline SIG_TIPO_PROPOSICAO & 2 & 2527.5 & 2565.5 & 0.874 & 0.6459 \\
\hline NUM LE- LEIS̄LATURA & 1 & 2501.5 & 2537.5 & 26.836 & 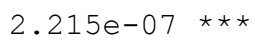 \\
\hline COĀIZAO & 9 & 2460.6 & 2512.7 & 67.729 & $4.238 e-11 \star \star \star *$ \\
\hline $\begin{array}{l}\text { AREA_TEMATICA } \\
---\end{array}$ & 451 & 2295.4 & 3231.4 & 233.007 & 1.0000 \\
\hline Significância: 0 '* & $\star \star \star * 1$ & $.001 \quad * x$ & $0.01 \cdot *$ & 05 '.' 0 & ' ' 1 \\
\hline
\end{tabular}

Fonte: Elaboração própria. Gl é o número de graus de liberdade. AIC (Akaike Information Criterion) é um teste comparativo cujos valores menores indicam modelos preferidos. LRT (Logistic Regresison Test) registra a variação do desvio entre o modelo original e o modelo com a adição da respectiva variável. 
Por outro lado, a adição de NUM_LEGISLATURA e COALIZAO são significativas e foram consideradas neste estudo, individualmente e em conjunto. O Quadro 5 ilustra a adição de NUM_LEGISLATURA ao modelo básico.

Quadro 5 - Modelo 2: IND_CONVERSAO_LEI $=\beta_{0}+\beta_{1} I N D \_C O R R U P C A O+\beta_{2}$ NUM_LEGISLATURA

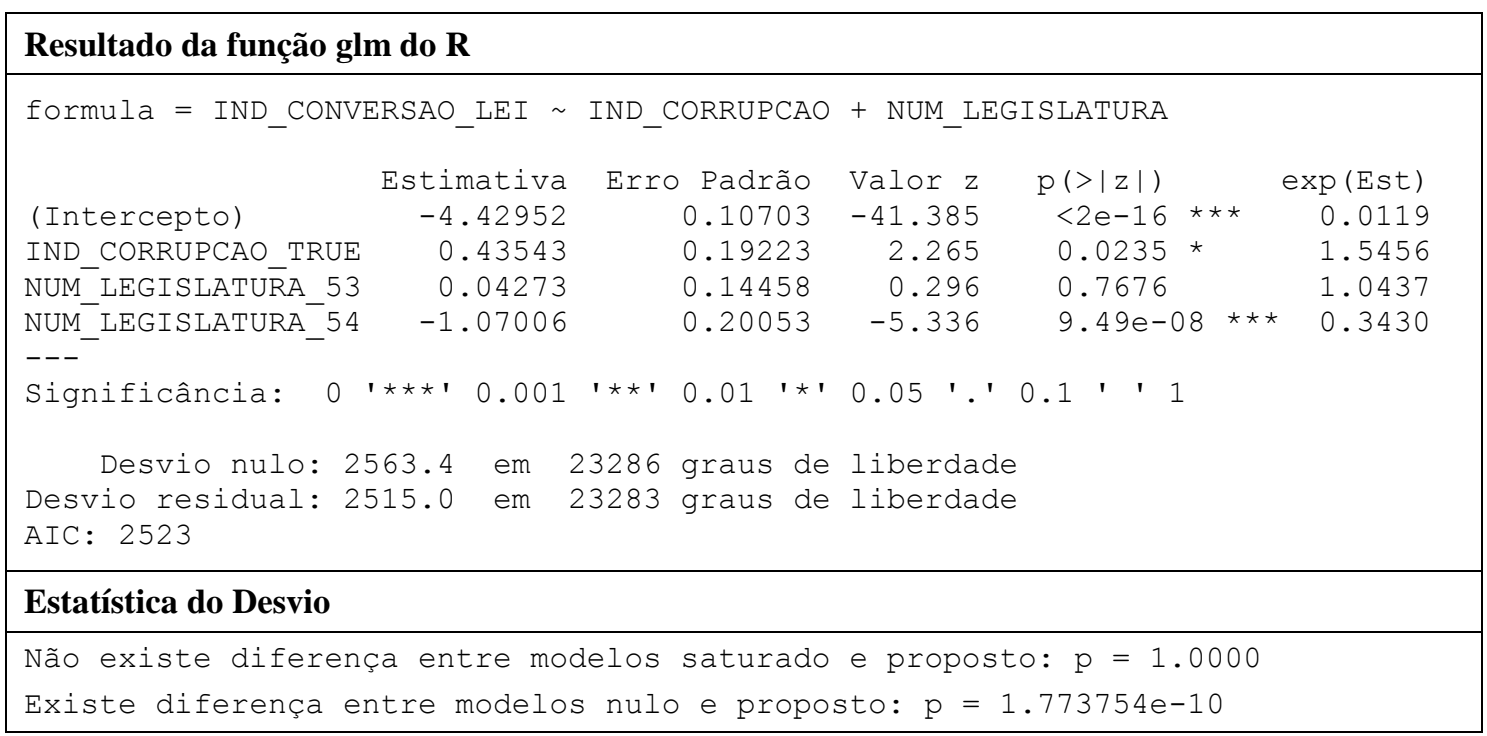

Fonte: Elaboração própria. A coluna exp(Est) foi incluída pelos autores e representa a função exponencial $e$, inversa da função logaritmo neperiano ln, para cada coeficiente estimado (coluna Estimativa).

Os resultados do Quadro 5 indicam que os coeficientes das legislaturas 52 (intercepto) e 54 são significativos e apontam para a redução da chance de conversão em lei. A coincidência desse fato é que os esquemas do Mensalão e da Lava Jato foram deflagrados, respectivamente, nas legislaturas 52 e 54, o que poderia ter freado o sucesso legislativo em função das instabilidades de cenário político geradas. Contudo, a inclusão da legislatura ao modelo não alterou substancialmente a influência do indicador de corrupção sobre a variável dependente. Neste modelo, o acréscimo da chance de parlamentar envolvido converter um projeto de lei em norma jurídica foi de $54,56 \%$, contra $57,08 \%$ no modelo básico. 
Quadro 6 - Modelo 3: IND_CONVERSAO_LEI $=\beta_{0}+\beta_{1} I N D \_C O R R U P C A O+\beta_{2} C O A L I Z A O$

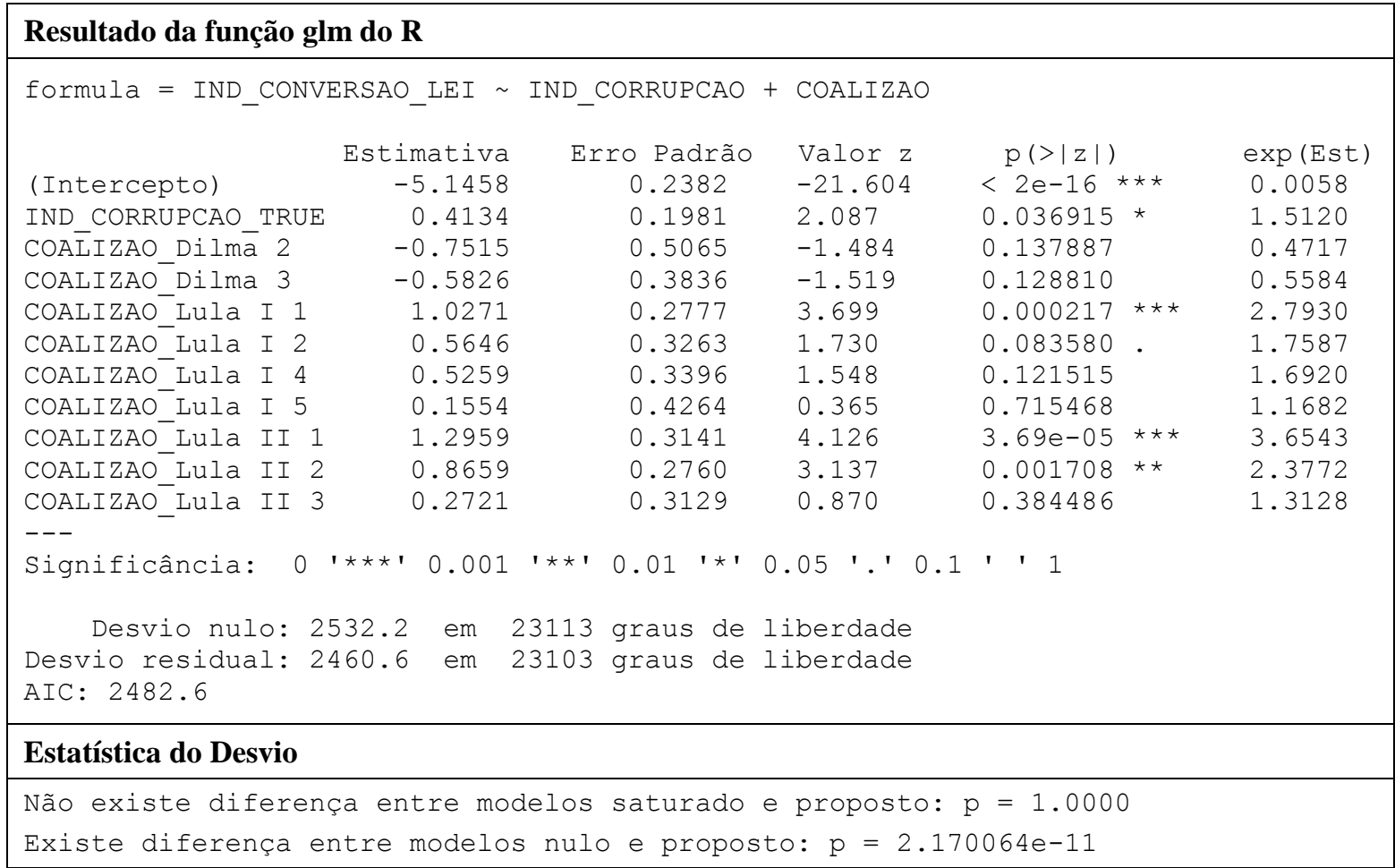

Fonte: Elaboração própria. A coluna exp(Est) foi incluída pelos autores e representa a função exponencial $e$, inversa da função logaritmo neperiano ln, para cada coeficiente estimado (coluna Estimativa).

O Quadro 6 apresenta coeficientes significativos para as coalizões "Lula I 1", "Lula I 2" ( $\mathrm{p}<0,1)$, "Lula II 1" e "Lula II 2", com aumento da chance de conversão em lei para todos os casos. Contrariamente, para as coalizões do governo Dilma, os coeficientes não são significativos e não produzem impacto em VD. Esse resultado parece refletir os perfis de cada governante: se por um lado o presidente Lula era reconhecido como habilidoso articulador político, por outro, a presidente Dilma ficou marcada pela incapacidade de dialogar com os atores políticos. Por muitas vezes, a Presidente deixara de receber deputados e senadores do próprio partido, o que levou o governo a perder votações e espaço para pautar agendas no Congresso Nacional. A inclusão dos dados de coalizão ao modelo também não alterou de forma substancial a influência do indicador de corrupção sobre VD. O acréscimo da chance de parlamentar envolvido converter um projeto de lei em norma jurídica passou a ser de 51,20\%.

Por fim, o Quadro 7 considera o modelo básico com a adição das duas variáveis de controle, caso em que o efeito da legislatura é anulado e apenas a coalizão "Lula I 1" aparece significativa. Novamente, o indicador de corrupção se mantém influente sobre a variação de VD, com acréscimo de chance em 51,18\%. 
Quadro 7 - Modelo 4: IND_CONVERSAO_LEI $=\beta_{0}+\beta_{1} I N D \_C O R R U P C A O+\beta_{2}$

NUM_LEGISLATURA $+\beta_{3}$ COALIZAO

\begin{tabular}{|c|c|c|c|c|c|}
\hline \multicolumn{6}{|c|}{ Resultado da função glm do $R$} \\
\hline \multicolumn{6}{|c|}{ formula $=$ IND_CONVERSAO_LEI $\sim$ IND_CORRUPCAO + NUM_LEGISLATURA + COALIZAO } \\
\hline & Estimativa & Erro Padrão & Valor z & $\mathrm{p}(>|\mathrm{z}|)$ & $\exp$ (Est) \\
\hline (Intercepto) & -4.9903 & 0.3565 & -14.000 & $<2 e-16 \star \star \star *$ & 0.0068 \\
\hline IND_CORRUPCAO_TRUE & 0.4133 & 0.1981 & 2.086 & $0.0370 \star$ & 1.5118 \\
\hline NUM_LEGISLATURA_53 & -8.5757 & 267.7058 & -0.032 & 0.9744 & 0.0002 \\
\hline NUM_LEGISLATURA_54 & -0.1542 & 0.4264 & -0.361 & 0.7177 & 0.8571 \\
\hline COĀ̄IZAO_Dilma $\overline{2}$ & -0.7528 & 0.5065 & -1.486 & 0.1372 & 0.4711 \\
\hline COALIZAO-Dilma 3 & -0.5839 & 0.3836 & -1.522 & 0.1280 & 0.5577 \\
\hline COALIZAO_Lula I 1 & 0.8717 & 0.3837 & 2.272 & $0.0231 *$ & 2.3909 \\
\hline COALIZAO Lula I 2 & 0.4091 & 0.4202 & 0.974 & 0.3302 & 1.5055 \\
\hline COALIZAO_Lula I 4 & 0.3704 & 0.4306 & 0.860 & 0.3896 & 1.4484 \\
\hline COALIZAO_Lula I 5 & NA & NA & NA & NA & NA \\
\hline COALIZAO_Lula II 1 & 9.7162 & 267.7057 & 0.036 & 0.9710 & 16583.60 \\
\hline COALIZAO_Lula II 2 & 9.2862 & 267.7056 & 0.035 & 0.9723 & 10788.27 \\
\hline COALIZAO_Lula II 3 & 8.6924 & 267.7057 & 0.032 & 0.9741 & 5957.54 \\
\hline \multicolumn{6}{|c|}{ Significância: 0 '***' 0.001 '**' 0.01 '*' 0.05 '.' 0.1 ' ' 1} \\
\hline \multicolumn{6}{|c|}{$\begin{array}{l}\text { Desvio nulo: } 2532.2 \text { em } 23113 \text { graus de liberdade } \\
\text { Desvio residual: } 2460.6 \mathrm{em} 23102 \text { graus de liberdade } \\
\text { AIC: } 2484.6\end{array}$} \\
\hline \multicolumn{6}{|l|}{ Estatística do Desvio } \\
\hline \multicolumn{6}{|c|}{$\begin{array}{l}\text { Não existe diferença entre modelos saturado e proposto: } p=1.0000 \\
\text { Existe diferença entre modelos nulo e proposto: } p=2.170064 \mathrm{e}-11\end{array}$} \\
\hline
\end{tabular}

Fonte: Elaboração própria. A coluna exp(Est) foi incluída pelos autores e representa a função exponencial $e$, inversa da função logaritmo neperiano ln, para cada coeficiente estimado (coluna Estimativa).

Pelo critério de informação de Akaike (AIC - Akaike Information Criterion), o modelo do Quadro 6 é ligeiramente melhor que o do Quadro 7. Contudo, o que merece atenção em todos os modelos é que nenhuma das variáveis de controle parece abalar o potencial explicativo do indicador de corrupção. Muito embora o desenho de pesquisa não permita identificar a precedência temporal de VI sobre VD, nem garantir totalmente que essa relação não seja espúria, condições necessárias para se estabelecer um mecanismo causal robusto, não se pode desconsiderar o relevante impacto de VI na variação de VD.

Portanto, diante do percentual expressivo no aumento das chances, torna-se importante compreender em que medida os parlamentares envolvidos já dispunham de algum prestígio político que pudesse levar ao resultado esperado. Nesse sentido, foram identificados 30 projetos, dentre os 213 convertidos em norma jurídica, cujas autorias eram de deputados com índice de corrupção marcado como verdadeiro. Desses, em apenas 7 (23,33\%) os autores ocupavam posição de destaque no ano em que os projetos foram convertidos em norma jurídica. Apesar do reconhecido poder de influência decorrente da ocupação dessas posições, esse fator não se revelou dominante no presente estudo.

Na sequência, foi empreendida análise comparada, de caráter descritivo, a partir desses 30 projetos, tomando-se por base o texto final sancionado, conforme relação disponível no 
Apêndice deste artigo. Adotou-se enfoque neoinstitucionalista de modo a aferir se, porventura, a produção legislativa desses deputados apresentou inclinação distributivista (ou paroquialista), isto é, leis que distribuem benefícios a certos setores econômicos identificáveis ou a uma região geográfica específica de onde o parlamentar provém.

Os estudos de Amorim-Neto e Santos (2003) e Lemos (2001) foram considerados para efeito de comparação com os dados da presente pesquisa. O primeiro avaliou a efetiva produção legislativa no período de 1982 a 1998, oriunda de projetos de lei de autoria de deputados, enquanto que o segundo se concentrou em projetos de autoria congressual (senadores e deputados), de 1991 a 2001, focando a área social. Em ambos, conclui-se que a produção legislativa não teve caráter distributivista, ou seja, em geral, as legislações de cunho nacional não favorecem região determinada ou classe setorial específica, produzindo efeitos transversais nos vários grupos sociais.

Amorim-Neto e Santos (2003) se valeram da tipologia de Taylor-Robinson (1999), utilizada para o estudo do parlamento de Honduras, que trata os projetos quanto ao nível de agregação e à natureza dos efeitos.

Sobre nível de agregação, entende-se que a legislação pode ser individual, quando tem por alvo apenas um ou poucos indivíduos, como, por exemplo, projetos que concedem pensões específicas a viúvas de ex-presidentes; local, quando tem por objeto um único ou poucos municípios, mas nunca a totalidade de municípios de um estado, região ou país; regional, quando tem por objeto um ou alguns estados ou regiões, mas não a totalidade dos estados ou regiões do país; setorial, quando tem por alvo um determinado setor da economia ou ramo de atividade profissional, por exemplo, projetos de regulamentação do exercício de uma nova profissão; e nacional, quando afeta sem distinções todos os grupos de cidadãos, regiões, estados e municípios.

Nesse aspecto, a comparação dos resultados do presente estudo com o de Amorim-Neto e Santos (2003) está ilustrada no Gráfico 1. 
Gráfico 1 - Comparação da proporção de leis quanto ao nível de agregação

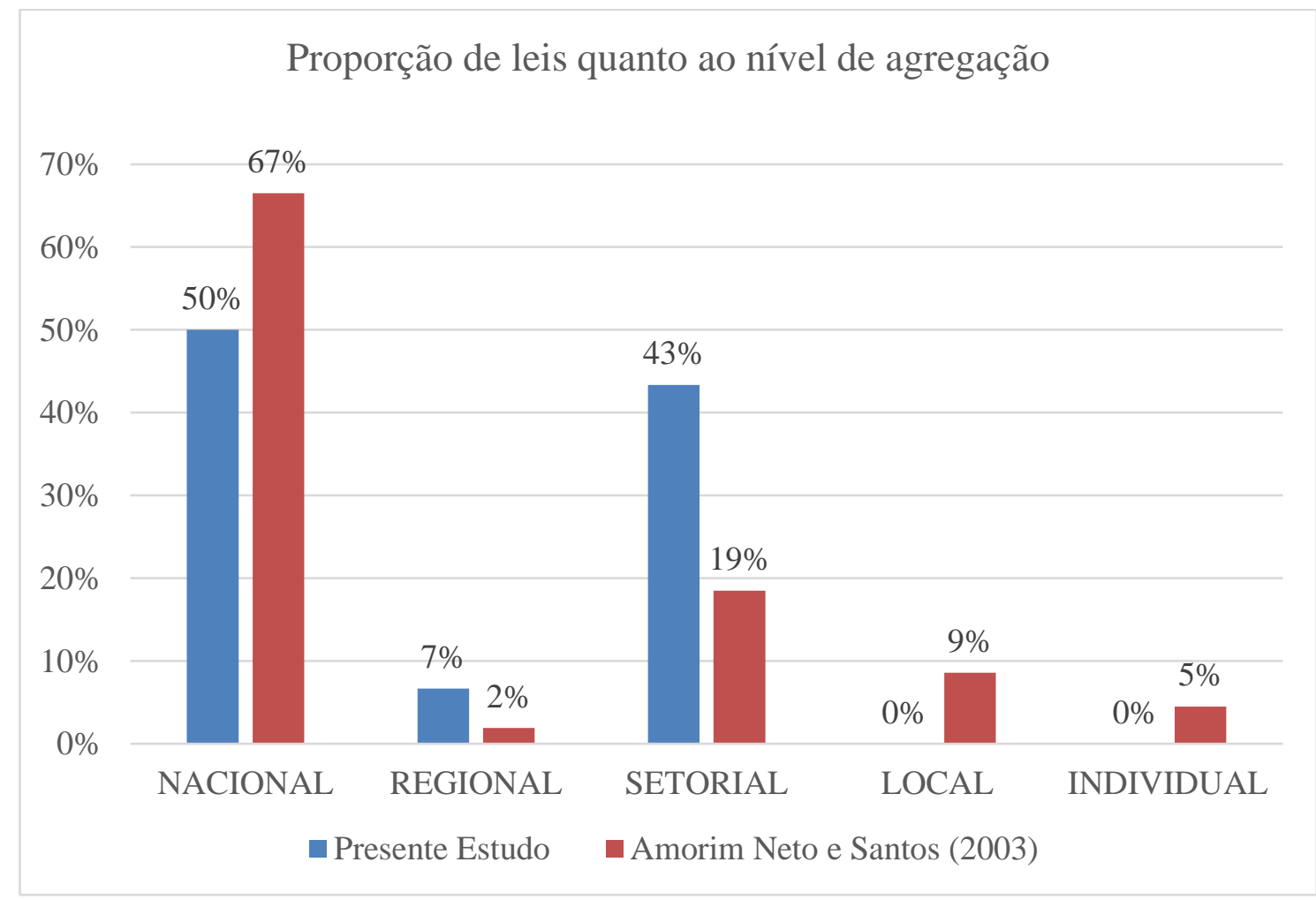

Fonte: Elaboração própria.

Constata-se, do Gráfico 1, que não houve projetos de cunho local ou individual aprovados por esses parlamentares, situação que pode ser associada ao fato de que projetos de caráter honorífico, os quais, muito frequentemente, rendem homenagens individuais ou localizadas geograficamente, inclusive em nível municipal, foram excluídos do universo deste estudo.

Por outro lado, verifica-se que os projetos classificados como setoriais representaram $43 \%$ do total, contra 19\% encontrados por Amorim-Neto e Santos (2003), o que pode configurar indício de que deputados supostamente associados à corrupção tendem a ver aprovada parcela mais substantiva de projetos dessa ordem.

Quanto à natureza dos efeitos, Amorim-Neto e Santos (2003) definem que a legislação pode ser benéfica, onerante, mista ou neutra. Benéfica, quando concede benefícios a um indivíduo, órgão, região, grupo social ou mesmo ao país como um todo. Onerante, quando impõe ônus financeiros ou regulatórios. Mista, quando ao mesmo tempo beneficia algumas pessoas e onera outras (por exemplo, uma legislação que impõe, a título de regulação, medidas para prevenir a deterioração do meio-ambiente é tida como mista, pois impõe ônus ao setor produtivo e, simultaneamente, visa alcançar benefícios ecológicos). Por último, a legislação é tida como neutra mormente nos projetos honoríficos e naqueles em que se busca especificar em detalhes um contrato ou legislação existente, concedendo maior segurança jurídica sem que se tenha o objetivo de prejudicar ou ajudar certas pessoas ou segmentos (AMORIM-NETO; SANTOS, 2003). 
Nesse aspecto, a análise exploratória do Gráfico 2 aponta para relativa convergência entre os estudos no que tange à proporção de projetos mistos (23\% contra $21 \%$ ) e revela queda para a metade dos onerantes (3\% contra $6 \%$ ). Já os projetos de natureza benéfica convertidos em lei representam aqui 37\% contra 49\% no estudo de Amorim-Neto e Santos (2003). Projetos com efeito neutro, que naquele estudo abrangem $23 \%$ da produção legal, correspondem neste a $37 \%$. Tendo em vista o crescimento percentual de projetos neutros - que não implicam ações que onerem, concedam ou redistribuam benefícios -, poder-se-ia concluir por um quadro de ausência de relação, ou relação fraca, entre a natureza dos efeitos e a possível associação a atos de corrupção. Contudo, tal crescimento vem acompanhado da redução de projetos benéficos para os quais, no presente estudo, predomina o caráter concentrado (ver Apêndice), ou seja, não distributivista, o que pode sugerir direcionamento.

Gráfico 2 - Comparação da proporção de leis quanto à natureza dos efeitos

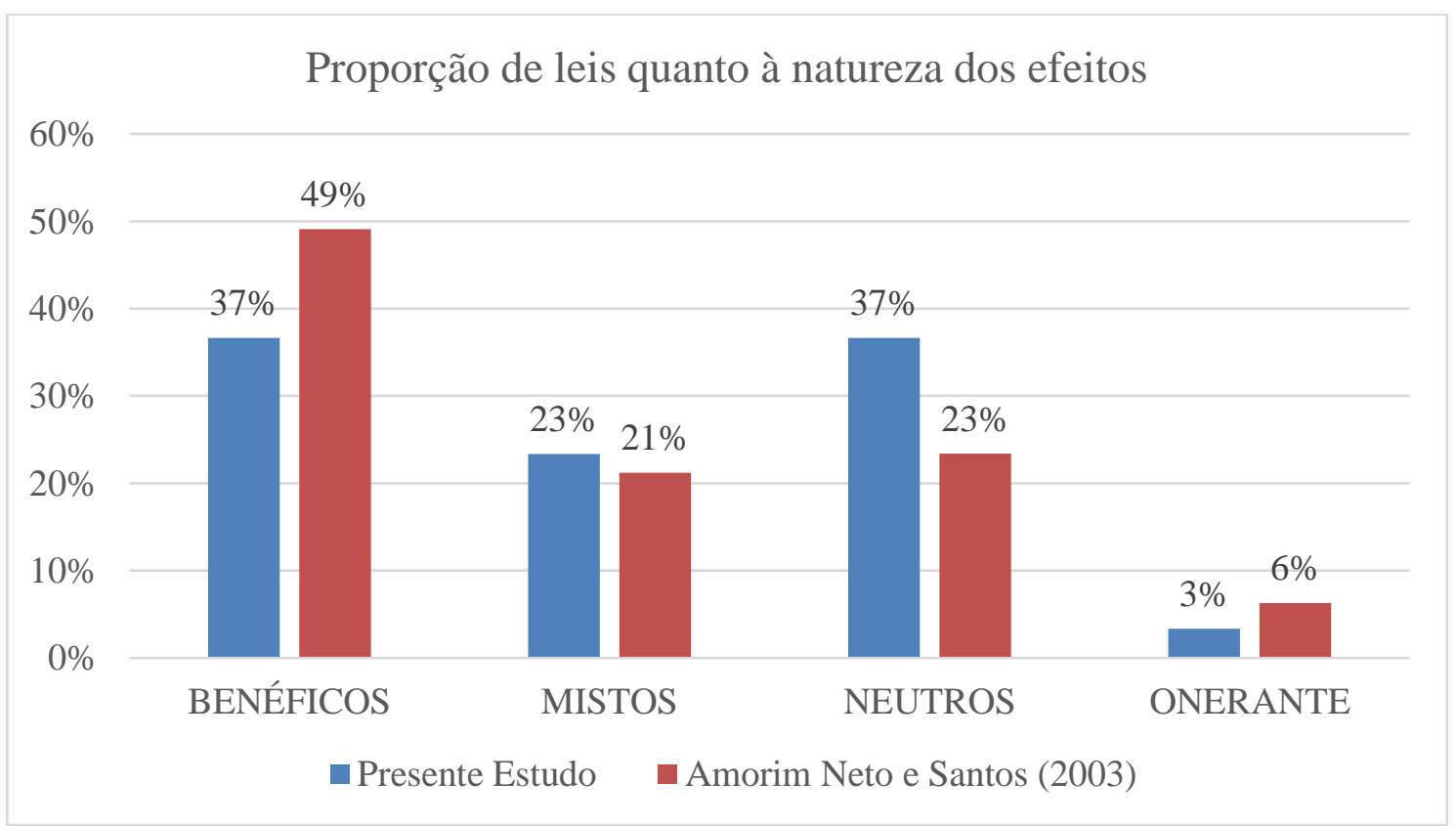

Fonte: Elaboração própria.

Lemos (2001), ao analisar a produção legislativa de temática social sob a ótica distributivista, considera duas dimensões: forma e escopo.

Quanto à forma, as leis são classificadas em legislação de regulação (da economia ou estabelecedora de regras procedimentais) e legislação de transferência de renda, patrimônio ou recursos da esfera federal para benefício de grupos, regiões e empresas.

No tocante a essa dimensão, os resultados, ilustrados no Gráfico 3, apresentam relativa convergência, sugerindo ausência de relação, ou relação fraca, entre a forma da lei e possível associação a atos de corrupção. 
Corrupção e sucesso legislativo: possíveis reflexos do mensalão e da lava jato na conversão de proposições em normas jurídicas

Gráfico 3 - Comparação da proporção de leis quanto à forma

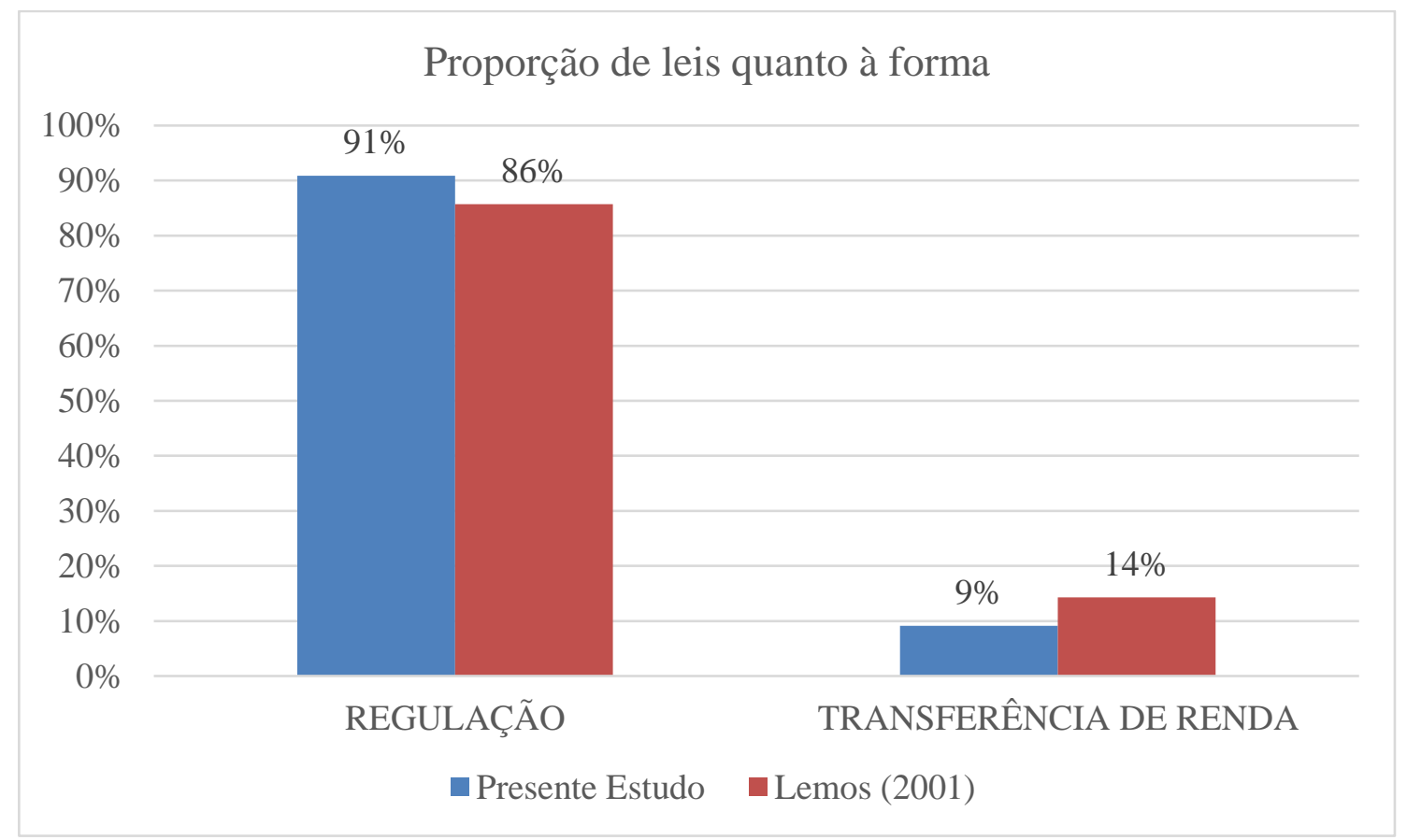

Fonte: Elaboração própria.

Quanto ao escopo, as leis se dividem em duas categorias: concentrada, que concede privilégios financeiros, patrimoniais, ou mesmo de status exclusivamente a um indivíduo, grupo, empresa ou localidade geográfica; difusa, que não diz respeito direto a indivíduos, empresas, grupos ou localidades, ou, quando o faz, tem por fito atenuar condições adversas, econômicas ou naturais, concedendo, assim, benefícios difusos.

Nesse aspecto, a comparação dos resultados do presente estudo com o de Lemos (2001) se destaca pela divergência dos achados, como ilustra o Gráfico 4. 
Gráfico 4 - Comparação da proporção de leis quanto ao escopo

Proporção de leis quanto ao escopo

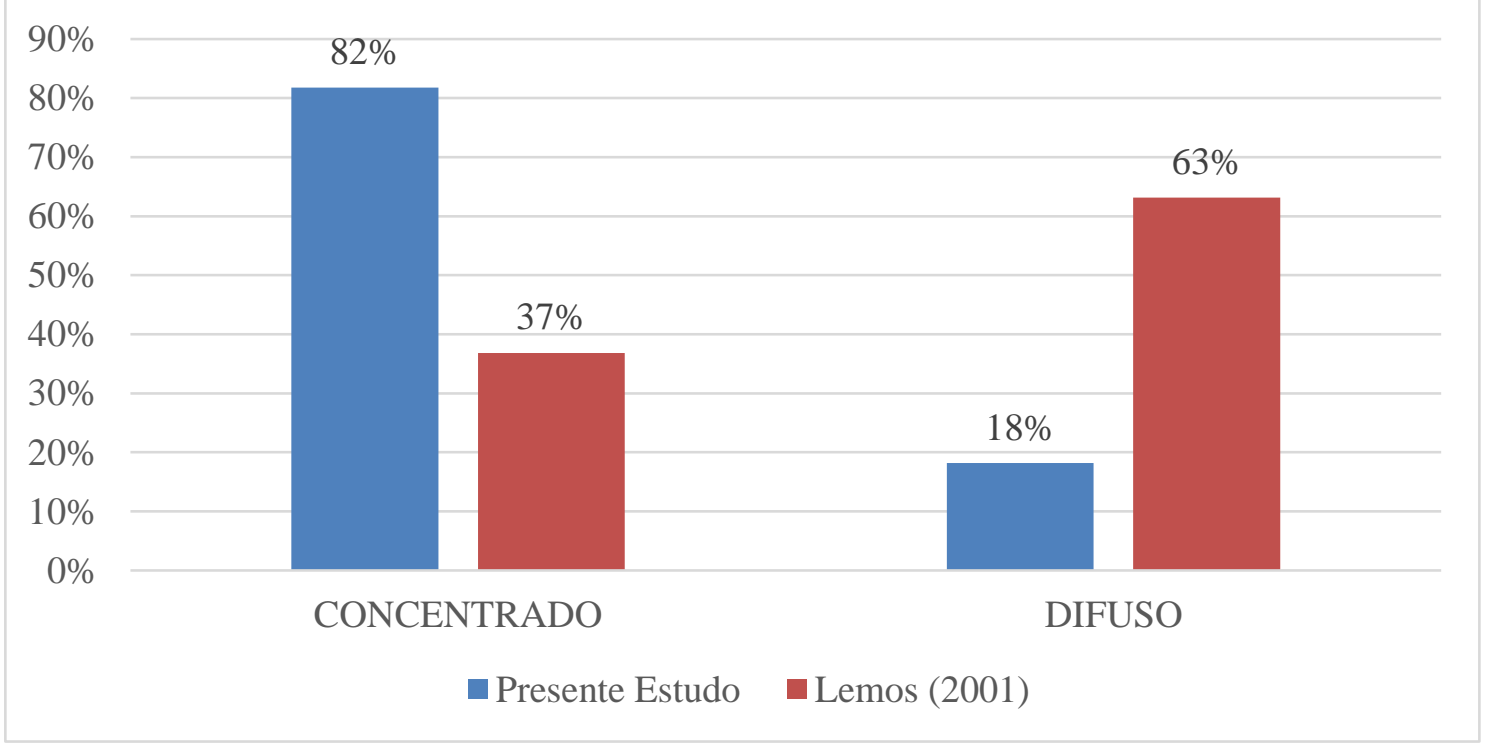

Fonte: Elaboração própria.

A partir do Gráfico 4, focando-se nos dados do presente estudo, pode-se considerar que o grupo de deputados citados tende a alcançar o sucesso legislativo em projetos na área social, cujos efeitos são mais concentrados que difusos. Esse resultado parece guardar certa similitude com o observado no Gráfico 1, o que indica uma atuação parlamentar predominantemente setorial, com efeitos e benefícios mais concentrados. Como exemplo, dos nove projetos convertidos em lei que eram da área social e tinham efeitos concentrados, sete foram classificados com nível de agregação setorial. É certo que tal atuação parlamentar poderia ser influenciada por grupos de pressão econômico-empresariais ou, também, por associações representativas de categorias profissionais. Contudo, a identificação dessas relações vai além do escopo deste estudo.

Em sentido oposto, os resultados de Lemos (2001) apontam para alta difusão e baixa concentração, tendência que parece mais alinhada com a intuição do que se espera para projetos da área social, cujo alcance, por definição, deve ser abrangente. Subentende-se dessa investigação exploratória que a inversão de gráficos encontrada no Gráfico 4 pode ser obra do objeto central do estudo, efeito do olhar detido sob a lupa da corrupção.

\section{Considerações finais}

Retornando à pergunta de pesquisa, sobre o impacto do envolvimento de parlamentar nos esquemas do Mensalão e da Lava Jato na taxa de conversão em norma jurídica de projetos de lei de sua autoria, é possível dizer, considerando-se a perspectiva do método quantitativo adotado, que foi revelado um percentual significativo de mais de $50 \%$ de aumento nas chances de se 
alcançar o sucesso legislativo, com influência menor da legislatura em que o projeto foi apresentado, da coalizão a que pertencia o parlamentar ou da posição por ele ocupada. Esse achado é um primeiro e importante passo, e fortalece a hipótese de que possíveis vantagens advindas de esquemas de corrupção tendem a favorecer a aprovação de projetos que atendam aos interesses desses esquemas.

Nesse sentido recorreu-se à análise qualitativa comparada, como recurso complementar de investigação, que apontou para uma conduta parlamentar com interesse setorial e de concentração de benefícios, características que parecem mais próximas de atos de corrupção. Apesar de a análise comparada aqui desenvolvida não ter sido sustentada por requisitos inferenciais, o que exigiria acesso pleno aos dados que fundamentaram os estudos utilizados nas comparações, o caráter descritivo da presente abordagem traz à luz elementos qualitativos que proporcionam compreensão mais apurada sobre a natureza dos projetos convertidos em norma jurídica. Esse entendimento é essencial na identificação de padrões de atuação capazes de sinalizar interesses específicos do grupo sob estudo, e representa contribuição importante em campo cujo espaço a ser explorado é amplo.

Já bem conhecidas são as dificuldades do processo legislativo em meio à desordem e complexidade estabelecida no sistema normativo brasileiro, causa precípua de grandes anomalias como lacunas e antinomias jurídicas. Lopes (2009) destaca que um fator relevante para esta torrente de produção legislativa é a necessidade que o legislador tem em atender as demandas eleitoreiras e, mesmo sem conhecimento do que realmente compõe o ordenamento jurídico, produz mais e mais normas, de forma inconsequente, baseadas apenas no oportunismo. Nesse cenário, qualquer vantagem na aprovação de projetos representa um diferencial competitivo.

Ressalta-se, no que diz respeito ao estabelecimento de relações causais robustas, que apenas o pressuposto de constatação da influência de VI sobre VD foi alcançado. Enormes desafios ainda rondam o atendimento aos dois outros pressupostos (PARANHOS et al, 2013). O da precedência temporal de VI sobre VD esbarra na dificuldade de mensuração direta do fenômeno, uma vez que cada fato apurado de corrupção goza de características próprias cuja aferição ocorre post factum (KUBBE, 2013, p. 43). O da não-espuriedade da relação requer levantamento vultuoso de dados e informações cuja magnitude extrapola o escopo de um único artigo ou esforço de pesquisa. No entanto, é claramente sabido que a aprovação de projetos constitui apenas um dos elementos do sucesso legislativo.

Ainda inquietante é o fato de que a corrupção, em suas diversas facetas, guarda mais variáveis espúrias do que aquelas que podem ser percebidas e explicadas pelos números deste estudo. A sociedade brasileira tem observado, "impotente", um panorama de corrupção endêmica em meio a tempestades institucionais que assolam os três poderes. Contudo, não podem ser ignorados os avanços recentes nas ações de transparência e de combate a atos ilícitos, as quais convergem para a construção de nova consciência coletiva, talvez o único caminho capaz de curar 
o mal em suas raízes.

Então, em perspectiva otimista, chegar-se-ia ao ponto em que o sucesso legislativo seria medido pelo sucesso de toda a sociedade.

\section{Referências}

AMORIM NETO, Octavio; SANTOS, Fabiano. O segredo ineficiente revisto: o que propõem e o que aprovam os deputados brasileiros? Dados. Rio de Janeiro, v. 46, n. 4, p. 61-698, 2003. Disponível em: http://www.scielo.br/pdf/dados/v46n4/a02v46n4.pdf. Acesso em: 18 jan. 2020.

ARAÚJO, Cletiane M.; COSTA, Saulo F.; FITTIPALDI, Ítalo. Boa noite, e boa sorte: determinantes da demissão de ministros envolvidos em escândalos de corrupção no primeiro governo Dilma Rousseff. Opinião Pública, v. 22, n. 1, p. 93-117, 2016.

\section{AVRITZER, Leonardo; FILGUEIRAS, Fernando. Corrupção e controles democráticos} no Brasil. São Paulo, 2011. Disponível em: https://www.ipea.gov.br/portal/images/stories/PDFs/TDs Ipea Cepal/tdcepal 032.pdf. Acesso em: 18 abr. 2020.

BANCO CENTRAL DO BRASIL. Indicadores econômicos consolidados. Brasília. 2017. Disponível em: https://www.bcb.gov.br/estatisticas/indecoreestruturacao. Acesso em: 14 maio 2018.

BARBOSA, Bernardo; MAIA, Gustavo. Lava jato: Fachin abre inquérito contra ministros e parlamentares; veja lista. UOL, p. 1-7. 2017. Disponível em:

https://noticias.uol.com.br/politica/ultimas-noticias/2017/04/11/lava-jato-fachin-abre-inqueritocontra-ministros-senadores-e-deputados-diz-jornal.htm. Acesso em: 18 jan. 2020.

BERTOT, John C.; JAEGER, Paul T.; GRIMES, Justin M. Using ICTs to create a culture of transparency: E-government and social media as openness and anti-corruption tools for societies. Government Information Quarterly, v. 27, n. 3, p. 264_271, 2010.

BRASIL. Câmara dos Deputados. Portal Corporativo - Dados Abertos - Dados de tramitação de proposições. 2019. Disponível em:

<http://www2.camara.leg.br/transparencia/dados-abertos/dados-abertoslegislativo/webservices/proposicoes-1>. Acesso em: 18 jan. 2020.

BRASIL. Câmara dos Deputados. Centro de Formação, Treinamento e Aperfeiçoamento. Repositório de Dados Públicos do Programa de Pós-Graduação da Câmara dos Deputados - Corrupção. Brasília. 2019. Disponível em: https://github.com/Cefor/corrupcao. Acesso em: 26 abr. 2020.

BRASIL. [Constituição (1988)]. Constituição da República Federativa do Brasil. Brasília, DF: Presidência da República, [2014]. Disponível em: http://www.planalto.gov.br/ccivil_03/constituicao/constituicaocompilado.htm. Acesso em: 14 maio 2018.

BRASIL. Controladoria-Geral da União. Portaria n. 1309, de 2013. Brasília. 2013a. Disponível em: http://www.lex.com.br/legis 24612602 PORTARIA N 1309 DE 15 DE JULHO DE 2013.aspx. Acesso em: 8 maio 2017.

BRASIL. Lei n. 8.072, de 25 de julho de 1.990. Brasília. 1990. Disponível em: http://www.planalto.gov.br/ccivil_03/leis/L8072compilada.htm. Acesso em: 14 maio 2018. 
BRASIL. Lei n. 12.527, de 18 de novembro de 2011. Brasília. 2011. Disponível em: http://www.planalto.gov.br/ccivil_03/_Ato2011-2014/2011/Lei/L12527.htm. Acesso em: 5 maio 2017.

BRASIL. Lei n. 12.846, de $\mathbf{1}^{\mathbf{0}}$ de agosto de 2013. Brasília. 2013b. Disponível em: http://www.planalto.gov.br/ccivil 03/ ato2011-2014/2013/lei/112846.htm. Acesso em: 14 maio 2018.

BRASIL. Lei Complementar n. 101, de 4 de maio de 2000. Estabelece normas de finanças públicas voltadas para a responsabilidade na gestão fiscal e dá outras providências. Brasília. 2000. Disponível em: http://www.planalto.gov.br/ccivil_03/leis/LCP/Lcp101.htm. Acesso em: 14 maio 2018.

BRASIL. Supremo Tribunal Federal. Ação Penal 470 Minas Gerais, de 17 de dezembro de 2.012. Brasília. 2012. Disponível em:

http://www.stf.jus.br/arquivo/informativo/documento/informativo693.htm. Acesso em: 14 maio 2018.

CALDAS, Olavo V.; COSTA, Cristiano M.; PAGLIARUSSI, Marcelo S. Corrupção e composição dos gastos governamentais: evidências a partir do programa de fiscalização por sorteios públicos da Controladoria-Geral da União. Revista de Administração Pública, v. 50, n. 2, p. 237-264, 2016.

CARVALHO, Janilton de. Diante de deputados, procurador da lava-jato compara corrupção a uma 'serial killer'. O Globo, p. 1-7. Rio de Janeiro. 2016. Disponível em:

https://oglobo.globo.com/brasil/diante-de-deputados-procurador-da-lava-jato-comparacorrupcao-uma-serial-killer-1-19558885. Acesso em: 14 maio 2018.

CEBRAP. Núcleo de Estudos Comparados e Internacionais - Dados Legislativos. São Paulo. 2019. Disponível em: http://neci.fflch.usp.br/legislative-data. Acesso em: 25 maio 2018.

APÓS CINCO anos, Laja jato soma controvérsias, 2.294 anos de penas e 159 condenados. Folha de São Paulo, São Paulo. 2019. Disponível em:

https://www1.folha.uol.com.br/poder/2019/03/apos-5-anos-lava-jato-soma-controversias-2294anos-de-penas-e-159-condenados.shtml. Acesso em: 18 abr. 2020.

CRONOLOGIA do Collorgate. Folha de São Paulo, São Paulo. 1995. Disponível em: http://www1.folha.uol.com.br/fsp/1995/5/01/brasil/24.html. Acesso em: 14 maio 2018.

FERES JÚNIOR, João; SASSARA, Luna de O. Corrupção, escândalos e a cobertura midiática da política. Novos Estudos CEBRAP, v. 35, n. 2, p. 205-225, 2016.

FIGUEIREDO, Argelina C.; LIMONGI, Fernando. Executivo e Legislativo na nova ordem constitucional. Rio de Janeiro: Editora FGV. 2001.

FIGUEIREDO, Marcelo. Os mais relevantes problemas político-eleitorais no Brasil (o sistema proporcional) e a luta contra a corrupção: do "Mensalão" à "Operação Lava Jato". Revista de Direito Administrativo, v. 277, n. 1, p. 399-436, 2018.

GUPTA, Sanjeev; MELLO, Luiz de; SHARAN, Raju. Corruption and military spending. European Journal of Political Economy, v. 17, n. 4, p. 749-777, 2001. 
HILBE, Joseph M. Logistic Regression Models. New York: CRC Press. 2009.

HUNTINGTON, Samuel P. Political Order in Changing Societies. New Haven: Yale University Press. 2006.

JOHNSTON, Michael. Corruption and democracy: threats to development, opportunities for reform. Hamilton - NY. 2000. Disponível em:

http://citeseerx.ist.psu.edu/viewdoc/summary?doi=10.1.1.572.8402. Acesso em: 18 maio 2018.

JOTA. Menos de 1\% das propostas apresentadas no Congresso viram lei. Brasília. 2019.

Disponível em: https://www.jota.info/paywall?redirect_to=//www.jota.info/dados/congressoprojetos-leis-12092019. Acesso em: 16 jan. 2020.

KNIRSCH, Thomas (ed.). Cadernos Adenauer, v.22, n.3. Ética pública e controle da corrupção. Rio de Janeiro: Fundação Konrad Adenauer. 2011.

KUBBE, Ina. Corruption in Europe in comparative perspective.2013. Tese (Doutorado em Ciência Política) - Leuphana Universität Lüneburg. 2013. Disponível em: http://dnb.info/1058767828/34. Acesso em: 8 maio 2020.

LEMOS, Lenay B. de S. O sistema de comissões no Senado brasileiro: hierarquia e concentração de poderes nos anos 90. In: LEMOS, L. B. (org.). O Senado Federal brasileiro no Pós-Constituinte. Brasília: Senado Federal. 2008. Disponível em:

http://www2.senado.leg.br/bdsf/item/id/180410. Acesso em: 18 maio 2018.

LEMOS, Leany B de S. O Congresso Brasileiro e a Distribuição de Benefícios Sociais no Período 1988-1994: Uma Análise Distributivista. Dados, Rio de Janeiro, v. 44, n. 3, p. 561-605, 2001. Disponível em: http://www.scielo.br/pdf/dados/v44n3/a04v44n3.pdf/. Acesso em 14 maio 2018.

LEÃO, Thaís. A lista de investigados da Lava-Jato no STF. O Globo, p. 1-3. Rio de Janeiro. 2016. Disponível em: http://infograficos.oglobo.globo.com/brasil/politicos-lava-jato.html. Acesso em: 18 jan. 2020.

LIMA, Amanda E. C. Do Mensalão à Lava Jato: os incidentes político-jurídicos da "parábola judiciária brasileira". In: ENCONTRO ANUAL DA ANPOCS, 42., Caxambu, 2018. Anais [...]. Disponível em: http://www.anpocs.com/index.php/encontros/papers/42-encontro-anual-daanpocs/spg-5/spg28-2/11510-do-mensalao-a-lava-jato-os-incidentes-politicos-juridicos-daparabola-judiciaria-brasileira/file. Acesso em 22 abr. de 2020.

LOPES, Flávia C. A. As dificuldades do processo legislativo de consolidação das leis. 2009. Trabalho de Conclusão de Curso (Especialização em Processo Legislativo) - Centro de Formação, Treinamento e Aperfeiçoamento, Câmara dos Deputados. 2009.

MATOS FILHO, Renato de S. Do Mensalão à Lava Jato: a ascensão da barganha e da colaboração premiada no processo penal. Revista de Ciências do Estado, Belo Horizonte, v. 2, n. 2, p. 411-421, 2017.

MAURO, Paolo. Corruption and the composition of government expenditure. Journal of Public Economics, v. 69, n. 2, p. 263-279, 1998.

MCMENAMIN, Iain. If money talks, what does it say? Varieties of capitalism and business financing of parties. World Politics, v. 64, n. 1, p. 1-38, 2012. 
MCNUTT, Marcia. Reproducibility. Science, v. 343, n. 6168, p. 229, 2014. Disponível em: http://science.sciencemag.org/content/343/6168/229.full. Acesso em: 18 maio 2018.

PARANHOS, Ranulfo, FIGUEIREDO FILHO, Dalson B., CARVALHO DA ROCHA, Enivaldo e SILVA JR, José A. Inferências causais falsificáveis em Ciência Política. Revista Eletrônica de Ciência Política, v. 4, n. 1-2, p. 264-283, 2013.

PEREIRA, Joelma e SARDINHA, Edson. Senado tem recorde de investigados: mais da metade dos senadores responde a acusações criminais no STF. Congresso em foco. Brasília. 2017. Disponível em: http://congressoemfoco.uol.com.br/noticias/senado-tem-recorde-deinvestigados-mais-da-metade-dos-senadores-responde-a-acusacoes-criminais-no-stf/. Acesso em: 14 maio 2018.

PERSSON, Anna, ROTHSTEIN, Bo e TEORELL. Why anticorruption reforms fail: systemic corruption as a collective action problem. Governance: An International Journal of Policy, Administration, and Institutions, v. 26, n. 3, p. 449-471, 2013.

PINTO-DUSCHINSKY, Michael. Financing politics: a global view. Journal of Democracy, v. 13, n. 4, p. 69-86, 2002.

POLVEIRO-JÚNIOR. Elton E. Desafios e perspectivas do Poder Legislativo no século XXI. Brasília. 2006. Disponível em: https://www12.senado.leg.br/publicacoes/estudoslegislativos/tipos-de-estudos/textos-para-discussao/td-30-desafios-e-perspectivas-do-poderlegislativo-no-seculo-xxi. Acesso em: 14 maio 2018.

PORTUGAL, Adriana C. Lobby pré-eleitoral e financiamento público de campanhas eleitorais: uma exploração em Economia Política Positiva. 2006. Tese (Doutorado em Economia) - Departamento de Economia, Universidade de Brasília, Brasília, 2006.

POWER, Timothy J.; TAYLOR, Matthew M. Accountability institutions and political corruption in Brazil. In: POWER, T. J.; TAYLOR, M. M. (ed.). Corruption and democracy in Brazil: the struggle for accountability. Indiana: University of Notre Dame Press, 2011. p. 1-28.

PRAÇA, Sérgio. Corrupção e reforma institucional no Brasil, 1988-2008. Opinião Pública, v. 17, n. 1, p. 137-162, 2011.

R7. MPF desarquiva investigação contra Lula por caso ligado ao mensalão. 2017.

Disponível em: https://noticias.r7.com/brasil/mpf-desarquiva-investigacao-contra-lula-por-casoligado-ao-mensalao-09082017. Acesso em: 21 abr. 2020.

RIBEIRO, Renato J. A sociedade contra o social: o alto custo da vida pública no Brasil. São Paulo: Companhia das Letras. 2000.

RICCI, Paolo e LEMOS, Leany Barreiro. Produção legislativa e preferências eleitorais na Comissão de Agricultura e Política Rural da Câmara dos Deputados. Revista Brasileira de Ciências Sociais, v. 19, n. 55, p. 107-129, 2004.

ROTHSTEIN, Bo e TEORELL, Jan. What is quality of government? A theory of impartial government institutions. Governance: An International Journal of Policy, Administration, and Institutions, v. 21, n. 2, p. 165-190, 2008.

RUBIO, Delia F. Financiamento de partidos e campanhas: Fundos públicos versus fundos privados. Novos Estudos, n. 73, p. 5-15, 2005. 
SANTOS, Fabiano. Deputados federais e instituições legislativas no Brasil: 1946-99. In: BOSCHI, Renato; DINIZ, Eli e SANTOS, Fabiano. (Ed.). Elites políticas e econômicas no Brasil contemporâneo: a desconstrução da ordem corporativa e o papel do legislativo no cenário pós-reformas. Rio de Janeiro: Fundação Konrad-Adenauer, 2000. p. 91-117.

SANTOS, Rafael F. dos; MEDEIROS, Danilo B.; SANTOS, Samuel M. Padrões de atuação das comissões do Congresso Nacional (1988-2006). In: ENCONTRO ANUAL DA ANPOCS, 32. 2008, Caxambu. Anais [...]: Disponível em: http://neci.fflch.usp.br/sites/neci.fflch.usp.br/files/freitas-medeiros-moura_2008Anpocs\%20(1).pdf. Acesso em 14 maio de 2018.

SANTOS, Rodrigo D. D. A Economia Política das Eleições 2002: Um estudo sobre a concentração de financiamento de campanha para deputado federal. 2009. Dissertação (Mestrado em Ciência Política) - Universidade Federal Fluminense. 2009.

SODRÉ, Antônio C. de A.; ALVES, Maria F. C. Relação entre emendas parlamentares e corrupção municipal no Brasil: estudo dos relatórios do programa de fiscalização da Controladoria-Geral da União. Revista de Administração Contemporânea, v. 14, n. 3, p. 414433, 2010.

SOUSA, Luís de; MORICONI, Marcelo. Why voters do not throw the rascals out?: A conceptual framework for analysing electoral punishment of corruption. Crime, Law and Social Change, v. 60, n. 5, p. 471-502, 2013.

SPECK, Bruno W. Mensurando a corrupção: uma revisão de dados provenientes de pesquisas empíricas. In: SPECK, Bruno W. et al. (ed.). Cadernos Adenauer n. 10: Os custos da corrupção. Fortaleza, CE: Fundação Konrad Adenauer, 2000. p. 1-40.

SPECK, Bruno W.; MARCIANO, João L. O perfil da Câmara dos Deputados pela ótica do financiamento das campanhas. In: SATHLER, André; BRAGA, Ricardo. (erg.). Legislativo pós-1988: Reflexões e perspectivas. Brasília: Câmara dos Deputados, 2015. p. 267-292. Disponível em: http:/bd.camara.gov.br/bd/handle/bdcamara/22179. Acesso em: 14 maio 2018.

TAVITS, Margit. Why do people engage in corruption? The case of Estonia. Social Forces, v. 88 , n. 3, p. $1257-1279,2010$.

TAYLOR-ROBINSON, Michelle M. e DIAZ, Cristopher. Who gets legislation passed in a Marginal Legislature and Is the label Marginal Legislature still appropriate? A study of the Honduran Congress. Comparative Political Studies, n. 32, p. 589-625, 1999.

TORRES, Marcelo D. de F. Estado, democracia e administração pública no Brasil. Rio de Janeiro: FGV. 2004.

TRANSPARENCY INTERNATIONAL. Global Corruption Barometer 2013. Berlim. 2013. Disponível em: http://www.transparency.org/gcb2013. Acesso em: 14 maio 2018.

TRÊS anos depois de abalar o país, Joesley Batista renegocia delação. Veja, São Paulo. 2020. Disponível em: https://veja.abril.com.br/noticias-sobre/operacao-lava-jato/. Acesso em 18 abr. 2020.

USLANER, Eric M.; ROTHSTEIN, Bo. The historical roots of corruption: State building, economic inequality, and mass education. Comparative Politics, v. 48, n. 2, p. 227-248, 2016. 
THE WAR against corruption in Latin America is in trouble. The Economist, 2019. Disponível em: https://www.economist.com/the-americas/2019/09/26/the-war-against-corruption-in-latinamerica-is-in-trouble. Acesso em: 18 abr. 2020.

\section{APÊNDICE}

Relação de Projetos Convertidos em lei analisados cujos autores tiveram o índice de corrupção marcado como verdadeiro

\begin{tabular}{|c|c|c|c|c|}
\hline Projeto & Ementa & $\begin{array}{c}\text { Lei } \\
\text { decorrente }\end{array}$ & Link & Classificação \\
\hline $\begin{array}{l}\text { PL } \\
5203 / 2009\end{array}$ & $\begin{array}{l}\text { DISPÕE SOBRE AS } \\
\text { COMISSÕES } \\
\text { INTERGESTORES DO } \\
\text { SISTEMA ÚNICO DE } \\
\text { SAÚDE E SUAS } \\
\text { RESPECTIVAS } \\
\text { COMPOSIÇÕES E DÁ } \\
\text { OUTRAS PROVIDÊNCIAS. }\end{array}$ & $\begin{array}{l}\text { Lei Ordinária } \\
12.466 / 2011\end{array}$ & $\begin{array}{l}\text { http://www.planalto.gov.b } \\
\text { r/ccivil_03/_ato2011- } \\
\text { 2014/2011/lei/112466.htm }\end{array}$ & $\begin{array}{l}\text { MISTO } \\
\text { REGULAÇÃO } \\
\text { DIFUSO }\end{array}$ \\
\hline $\begin{array}{l}\text { PL } \\
1089 / 2003\end{array}$ & $\begin{array}{l}\text { ALTERA DISPOSITIVOS DO } \\
\text { DECRETO-LEI N }{ }^{\circ} 467, \text { DE } 13 \\
\text { DE FEVEREIRO DE } 1969, \\
\text { ESTABELECE O } \\
\text { MEDICAMENTO } \\
\text { GENÉRICO PARA USO } \\
\text { VETERINÁRIO, DISPÕE } \\
\text { SOBRE A UTILIZAÇÃO DE } \\
\text { NOMES GENERICOS EM } \\
\text { PRODUTOS } \\
\text { FARMACÊUTICOS DE USO } \\
\text { VETERINÁRIO E DÁ } \\
\text { OUTRAS PROVIDÊNCIAS. }\end{array}$ & $\begin{array}{l}\text { Lei Ordinária } \\
12.689 / 2012\end{array}$ & $\frac{\frac{\text { http://www.planalto.gov.b }}{\text { r/ccivil_03/_Ato2011- }}}{\frac{\text { 2014/2012/Lei/L12689.ht }}{\mathrm{m}}}$ & $\begin{array}{l}\text { MISTO } \\
\text { REGULAÇÃO } \\
\text { DIFUSO }\end{array}$ \\
\hline $\begin{array}{l}\text { PL } \\
4280 / 2008\end{array}$ & $\begin{array}{l}\text { DISPÕE SOBRE O } \\
\text { EXERCÍCIO DA } \\
\text { ATIVIDADE E A } \\
\text { REMUNERAÇÃO DO } \\
\text { PERMISSIONÁRIO } \\
\text { LOTÉRICO, FIXA } \\
\text { CONDIÇÕES PARA SUA } \\
\text { ATUAÇÃO COMO } \\
\text { CORRESPONDENTE } \\
\text { BANCÁRIO, E DÁ OUTRAS } \\
\text { PROVIDÊNCIAS. } \\
\end{array}$ & $\begin{array}{l}\text { Lei Ordinária } \\
12.869 / 2013\end{array}$ & $\begin{array}{l}\frac{\text { http://www.planalto.gov.b }}{\text { r/ccivil_03/ato2011- }} \\
\underline{\text { 2014/2013/lei/L12869.ht }} \\
\underline{m}\end{array}$ & $\begin{array}{l}\text { NÊUTRO } \\
\text { REGULAÇÃO } \\
\text { DIFUSO }\end{array}$ \\
\hline $\begin{array}{l}\text { PL } \\
1015 / 2007\end{array}$ & $\begin{array}{l}\text { ACRESCENTA } \\
\text { DISPOSITIVO AO ART. } 158 \\
\text { DO CÓDIGO DE TRÂNSITO } \\
\text { BRASILEIRO, PARA } \\
\text { TORNAR OBRIGATÓRIA } \\
\text { APRENDIZAGEM } \\
\text { NOTURNA. }\end{array}$ & $\begin{array}{l}\text { Lei Ordinária } \\
12.217 / 2010\end{array}$ & $\begin{array}{l}\frac{\mathrm{http} / / \text { www.planalto.gov.b }}{\mathrm{r} / \mathrm{ccivil} \text { 03/Ato2007- }} \\
\underline{\text { 2010/2010/Lei/L12217.ht }} \\
\underline{\mathrm{m}}\end{array}$ & $\begin{array}{l}\text { MISTO } \\
\text { REGULAÇÃO } \\
\text { DIFUSO }\end{array}$ \\
\hline $\begin{array}{l}\text { PL } \\
3883 / 2004\end{array}$ & $\begin{array}{l}\text { ACRESCENTA INCISO AO } \\
\text { ART. 473 DA } \\
\text { CONSOLIDAÇÃO DAS LEIS } \\
\text { DO TRABALHO, } \\
\text { APROVADA PELO } \\
\text { DECRETO-LEI N }{ }^{\circ} 5.452, \text { DE } \\
1^{\circ} \text { DE MAIO DE } 1943, \text { PARA } \\
\text { PERMITIR A AUSÊNCIA DO } \\
\text { TRABALHADOR AO } \\
\text { SERVIÇO, SEM PREJUÍZO }\end{array}$ & $\begin{array}{l}\text { Lei Ordinária } \\
11.304 / 2006\end{array}$ & $\begin{array}{l}\frac{\mathrm{http} / / \text { www.planalto.gov.b }}{\mathrm{r} / \mathrm{ccivil} \text { 03/_ato2004- }} \\
\underline{\text { 2006/2006/lei/L11304.ht }} \\
\underline{\mathrm{m}}\end{array}$ & $\begin{array}{l}\text { BENÉFICO } \\
\text { REGULAÇÃO } \\
\text { CONCENTRA } \\
\text { DO }\end{array}$ \\
\hline
\end{tabular}




\begin{tabular}{|c|c|c|c|c|}
\hline & $\begin{array}{l}\text { DO SALÁRIO, NA } \\
\text { HIPÓTESE DE } \\
\text { PARTICIPAÇÃO EM } \\
\text { REUNIÃO DE ORGANISMO } \\
\text { INTERNACIONAL AO } \\
\text { QUAL O BRASIL SEJA } \\
\text { FILIADO. } \\
\text { NOVA EMENTA DA } \\
\text { REDAÇÃO FINAL : } \\
\text { ACRESCENTA INCISO AO } \\
\text { ART. 473 DA } \\
\text { CONSOLIDAÇÃO DAS LEIS } \\
\text { DO TRABALHO - CLT, } \\
\text { APROVADA PELO } \\
\text { DECRETO-LEI N } 5.452, \text { DE } \\
1^{\circ} \text { DE MAIO DE 1943, PARA } \\
\text { PERMITIR A AUSÊNCIA DO } \\
\text { TRABALHADOR AO } \\
\text { SERVIÇO, SEM PREJUÍZO } \\
\text { DO SALÁRIO, NA } \\
\text { HIPÓTESE DE } \\
\text { PARTICIPAÇÃO EM } \\
\text { REUNIÃO OFICIAL DE } \\
\text { ORGANISMO } \\
\text { INTERNACIONAL AO } \\
\text { QUAL O BRASIL SEJA } \\
\text { FILIADO. } \\
\end{array}$ & & & \\
\hline $\begin{array}{l}\text { PL } \\
6483 / 2006\end{array}$ & $\begin{array}{l}\text { DISPÕE SOBRE O } \\
\text { FORNECIMENTO DE } \\
\text { ALIMENTAÇÃO } \\
\text { DIFERENCIADA PARA } \\
\text { CRIANÇAS E } \\
\text { ADOLESCENTES } \\
\text { PORTADORES DE } \\
\text { DIABETES NAS ESCOLAS } \\
\text { PÚBLICAS BRASILEIRAS. } \\
\end{array}$ & $\begin{array}{l}\text { Lei Ordinária } \\
12.982 / 2014\end{array}$ & $\frac{\frac{\text { http://www.planalto.gov.b }}{\text { r/ccivil 03/Ato2011- }}}{\underline{\text { 2014/2014/Lei/L12982.ht }}}$ & $\begin{array}{l}\text { BENÉFICO } \\
\text { REGULAÇÃO } \\
\text { CONCENTRA } \\
\text { DO }\end{array}$ \\
\hline $\begin{array}{l}\text { PL } \\
6785 / 2006\end{array}$ & $\begin{array}{l}\text { DISPÕE SOBRE A } \\
\text { OBRIGATORIEDADE DOS } \\
\text { SERVIÇOS DE REGISTROS } \\
\text { CIVIS DE PESSOAS } \\
\text { NATURAIS COMUNICAR À } \\
\text { RECEITA FEDERAL E À } \\
\text { SECRETARIA DE } \\
\text { SEGURANÇA PÚBLICA OS } \\
\text { ÓBITOS REGISTRADOS. } \\
\end{array}$ & $\begin{array}{l}\text { Lei Ordinária } \\
13.114 / 2015\end{array}$ & $\begin{array}{l}\frac{\text { http://www.planalto.gov.b }}{\text { r/ccivil_03/_ato2015- }} \\
\text { 2018/2015/lei/113114.htm }\end{array}$ & $\begin{array}{l}\text { MISTO } \\
\text { REGULAÇÃO } \\
\text { DIFUSO }\end{array}$ \\
\hline $\begin{array}{l}\text { PL } \\
6303 / 2005\end{array}$ & $\begin{array}{l}\text { ALTERA A EMENTA DO } \\
\text { DECRETO-LEI No } 4.657, \text { DE } \\
4 \text { DE SETEMBRO DE } 1942 .\end{array}$ & $\begin{array}{l}\text { Lei Ordinária } \\
12.376 / 2010\end{array}$ & $\begin{array}{l}\frac{\text { http://www.planalto.gov.b }}{\mathrm{r} / \mathrm{ccivil} \text { 03/Ato2007- }} \\
\underline{\text { 2010/2010/Lei/L12376.ht }} \\
\underline{\underline{\mathrm{m}}}\end{array}$ & $\begin{array}{l}\text { NÊUTRO } \\
\text { REGULAÇÃO } \\
\text { DIFUSO }\end{array}$ \\
\hline $\begin{array}{l}\text { PL } \\
7410 / 2010\end{array}$ & $\begin{array}{l}\text { ALTERA O } \$ 9^{\circ} \text { DO ART. } 8^{\circ}- \\
\text { E, DA LEI N } 11.530, \text { DE } 24 \\
\text { DE OUTUBRO DE } 2007, \\
\text { PARA INCLUIR OS } \\
\text { AGENTES DE TRÂNSITO } \\
\text { ENTRE OS BENEFICIÁRIOS } \\
\text { DO PROGRAMA BOLSA- } \\
\text { FORMAÇÃO. } \\
\end{array}$ & $\begin{array}{l}\text { Lei Ordinária } \\
13.030 / 2014\end{array}$ & $\frac{\frac{\text { http://www.planalto.gov.b }}{\mathrm{r} / \mathrm{ccivil} \text { 03/Ato2011- }}}{\underline{\underline{\text { 2014/2011/Lei/L12467.ht }}}}$ & $\begin{array}{l}\text { BENÉFICO } \\
\text { T. RENDA } \\
\text { CONCENTRA } \\
\text { DO }\end{array}$ \\
\hline $\begin{array}{l}\text { PL } \\
4495 / 2008\end{array}$ & $\begin{array}{l}\text { DISPÕE SOBRE } \\
\text { REGULAMENTAÇÃO DO } \\
\text { EXERCÍCIO DA PROFISSÃO }\end{array}$ & $\begin{array}{l}\text { Lei Ordinária } \\
12.467 / 2011\end{array}$ & $\begin{array}{l}\text { http://www.planalto.gov.b } \\
\text { r/ccivil_03/_ato2011- } \\
\text { 2014/2011/lei/L12467.ht } \\
\end{array}$ & \begin{tabular}{|l|} 
BENÉFICO \\
REGULAÇÃO \\
CONCENTRA \\
\end{tabular} \\
\hline
\end{tabular}




\begin{tabular}{|c|c|c|c|c|}
\hline & DE "SOMMELIER". & & $\underline{\mathrm{m}}$ & DO \\
\hline $\begin{array}{l}\text { PL } \\
4591 / 2004\end{array}$ & $\begin{array}{l}\text { ALTERA A LEI No } 10.482, \\
\text { DE } 3 \text { DE JULHO DE } 2002, \\
\text { QUE DISPÕE SOBRE OS } \\
\text { DEPÓSITOS JUDICIAIS E } \\
\text { EXTRAJUDICIAIS DE } \\
\text { TRIBUTOS, NO ÂMBITO } \\
\text { DOS ESTADOS E DO } \\
\text { DISTRITO FEDERAL E DÁ } \\
\text { OUTRAS PROVIDÊNCIAS. }\end{array}$ & $\begin{array}{l}\text { Lei Ordinária } \\
11.429 / 2006\end{array}$ & $\frac{\frac{\mathrm{http}: / / \text { www.planalto.gov.b }}{\mathrm{r} / \mathrm{ccivil} \text { 03/ ato2004- }}}{\text { 2006/2006/lei/111429.htm }}$ & $\begin{array}{l}\text { NÊUTRO } \\
\text { REGULAÇÃO } \\
\text { DIFUSO }\end{array}$ \\
\hline $\begin{array}{l}\text { PL } \\
2977 / 2004\end{array}$ & $\begin{array}{l}\text { CRIA A } \\
\text { OBRIGATORIEDADE DE } \\
\text { REALIZAÇÃO DE EXAMES } \\
\text { MÉDICOS TRIMESTRAIS } \\
\text { PARA OS ATLETAS } \\
\text { BRASILEIROS A FIM DE } \\
\text { VERIFICAR A SAÚDE, E } \\
\text { CRIA A COMISSÃO } \\
\text { ESPORTIVA DE } \\
\text { PREVENÇÃO E } \\
\text { ASSISTÊNCIA DE } \\
\text { ACIDENTES DESPORTIVOS } \\
\text { - CEPAAD. }\end{array}$ & $\begin{array}{l}\text { Lei Ordinária } \\
12.346 / 2010 .\end{array}$ & $\begin{array}{l}\frac{\text { http://www.planalto.gov.b }}{\text { r/ccivil 03/Ato2007- }} \\
\underline{\text { 2010/2010/Lei/L12346.ht }} \\
\underline{\mathrm{m}}\end{array}$ & $\begin{array}{l}\text { BENÉFICO } \\
\text { REGULAÇÃO } \\
\text { CONCENTRA } \\
\text { DO }\end{array}$ \\
\hline $\begin{array}{l}\text { PL } \\
7409 / 2010\end{array}$ & $\begin{array}{l}\text { DISPÕE SOBRE A } \\
\text { OBRIGATORIEDADE DAS } \\
\text { AGÊNCIAS DE } \\
\text { AUTOMÓVEIS, NOVOS OU } \\
\text { USADOS, INFORMAREM O } \\
\text { VALOR DOS TRIBUTOS E } \\
\text { EVENTUAIS MULTAS } \\
\text { PARA QUE O VEÍCULO } \\
\text { POSSA CIRCULAR } \\
\text { LIVREMENTE. }\end{array}$ & $\begin{array}{l}\text { Lei Ordinária } \\
13.111 / 2015\end{array}$ & $\begin{array}{l}\frac{\mathrm{http}: / / \text { www.planalto.gov.b }}{\mathrm{r} / \mathrm{ccivil} \text { 03/ Ato2015- }} \\
\underline{\text { 2018/2015/Lei/L13111.ht }} \\
\underline{\mathrm{m}}\end{array}$ & $\begin{array}{l}\text { MISTO } \\
\text { REGULAÇÃO } \\
\text { DIFUSO }\end{array}$ \\
\hline $\begin{array}{l}\text { PL } \\
5498 / 2009\end{array}$ & $\begin{array}{l}\text { ALTERA A LEI No } 9.096, \text { DE } \\
19 \text { DE SETEMBRO DE } 1995 \\
\text { (LEI DOS PARTIDOS } \text { POLÍTICOS) E A LEI No } \\
\text { 9.504, DE 30 DE SETEMBRO } \\
\text { DE 1997, QUE } \\
\text { "ESTABELECE NORMAS } \\
\text { PARA AS ELEIÇÕES". }\end{array}$ & $\begin{array}{l}\text { Lei Ordinária } \\
12.034 / 2009\end{array}$ & $\begin{array}{l}\frac{\text { http://www.planalto.gov.b }}{\text { r/ccivil_03/ato2007- }} \\
\text { 2010/2009/lei/112034.htm }\end{array}$ & $\begin{array}{l}\text { NÊUTRO } \\
\text { REGULAÇÃO } \\
\text { DIFUSO }\end{array}$ \\
\hline PL 84/2007 & $\begin{array}{l}\text { ALTERA A LEI No 9.096, DE } \\
\text { 1995, PARA } \\
\text { ESTABELECIMENTO DO } \\
\text { CRITÉRIO DE } \\
\text { DISTRIBUIÇÃO DO FUNDO } \\
\text { PARTIDÁRIO. }\end{array}$ & $\begin{array}{l}\text { Lei Ordinária } \\
11.459 / 2007\end{array}$ & $\begin{array}{l}\frac{\text { http://www.planalto.gov.b }}{\mathrm{r} / \mathrm{ccivil} \text { 03/_Ato2007- }} \\
\underline{\text { 2010/2007/Lei/L11459.ht }} \\
\underline{\mathrm{m}}\end{array}$ & $\begin{array}{l}\text { NÊUTRO } \\
\text { REGULAÇÃO } \\
\text { DIFUSO }\end{array}$ \\
\hline $\begin{array}{l}\text { PL } \\
4246 / 2012\end{array}$ & $\begin{array}{l}\text { DISPÕE SOBRE O } \\
\text { EXERCICIO DA PROFISSÃO } \\
\text { DE MOTORISTA. }\end{array}$ & $\begin{array}{l}\text { Lei Ordinária } \\
13.103 / 2015\end{array}$ & $\begin{array}{l}\frac{\text { http://www.planalto.gov.b }}{\mathrm{r} / \mathrm{ccivil} \text { 03/ato2015- }} \\
\underline{\text { 2018/2015/lei/113103.htm }}\end{array}$ & $\begin{array}{l}\text { MISTO } \\
\text { REGULAÇÃO } \\
\text { CONCENTRA } \\
\text { DO }\end{array}$ \\
\hline
\end{tabular}




\begin{tabular}{|c|c|c|c|c|}
\hline $\begin{array}{l}\text { PLP } \\
123 / 2004\end{array}$ & 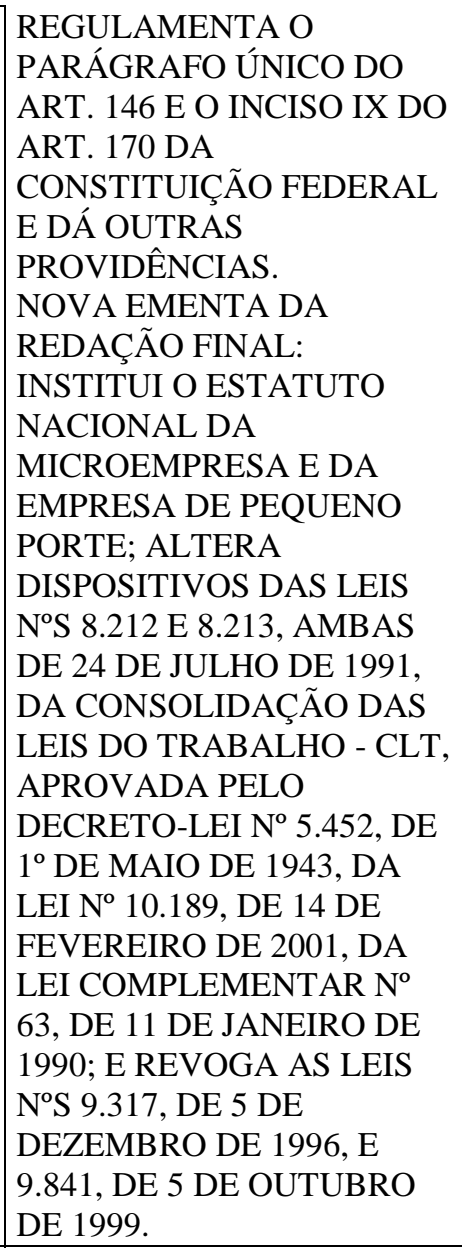 & $\begin{array}{l}\text { Lei } \\
\text { Complementar } \\
\text { 123/2006 }\end{array}$ & $\begin{array}{l}\frac{\text { http://www.planalto.gov.b }}{\text { r/ccivil_03/leis/LCP/Lcp1 } 1} \\
\underline{\underline{23 . h t m}}\end{array}$ & $\begin{array}{l}\text { BENÉFICO } \\
\text { REGULAÇÃO } \\
\text { CONCENTRA } \\
\text { DO }\end{array}$ \\
\hline $\begin{array}{l}\text { PL } \\
2742 / 2003\end{array}$ & $\begin{array}{l}\text { PRORROGA O PRAZO } \\
\text { PARA QUE SEJAM } \\
\text { RATIFICADAS AS } \\
\text { CONCESSÕES E } \\
\text { ALIENAÇÕES DE TERRAS } \\
\text { FEITAS PELOS ESTADOS } \\
\text { EM FAIXA DE FRONTEIRA, } \\
\text { E DÁ OUTRAS } \\
\text { PROVIDÊNCIAS } \\
\end{array}$ & $\begin{array}{l}\text { Lei Ordinária } \\
13.178 / 2015\end{array}$ & $\begin{array}{l}\frac{\text { http://www.planalto.gov.b }}{\text { r/ccivil 03/Ato2015- }} \\
\underline{\underline{2018 / 2015 / \text { Lei/L13178.ht }}} \\
\underline{\underline{m}}\end{array}$ & $\begin{array}{l}\text { NÊUTRO } \\
\text { REGULAÇÃO } \\
\text { DIFUSO }\end{array}$ \\
\hline $\begin{array}{l}\text { PL } \\
6316 / 2009\end{array}$ & $\begin{array}{l}\text { DISPÕE SOBRE A } \\
\text { INSTALAÇÃO DE FREE } \\
\text { SHOPPING NAS FAIXAS DE } \\
\text { FRONTEIRA. }\end{array}$ & $\begin{array}{l}\text { Lei Ordinária } \\
12.723 / 2012\end{array}$ & $\begin{array}{l}\frac{\text { http://www.planalto.gov.b }}{\mathrm{r} / \mathrm{ccivil} \text { 03/Ato2011- }} \\
\underline{\text { 2014/2012/Lei/L12723.ht }} \\
\underline{\mathrm{m}}\end{array}$ & $\begin{array}{l}\text { BENÉFICO } \\
\text { REGULAÇÃO } \\
\text { CONCENTRA } \\
\text { DO }\end{array}$ \\
\hline $\begin{array}{l}\text { PL } \\
4673 / 2004\end{array}$ & $\begin{array}{l}\text { RECONHECE A PROFISSÃO } \\
\text { DE INTÉRPRETE DA } \\
\text { LÍNGUA BRASILEIRA DE } \\
\text { SINAIS - LIBRAS E DÁ } \\
\text { OUTRAS PROVIDÊNCIAS. }\end{array}$ & $\begin{array}{l}\text { Lei Ordinária } \\
12.319 / 2010\end{array}$ & $\begin{array}{l}\frac{\text { http://www.planalto.gov.b }}{\text { r/ccivil 03/ato2007- }} \\
\text { 2010/2010/lei/112319.htm }\end{array}$ & $\begin{array}{l}\text { NÊUTRO } \\
\text { REGULAÇÃO } \\
\text { CONCENTRA } \\
\text { DO }\end{array}$ \\
\hline $\begin{array}{l}\text { PL } \\
7639 / 2010\end{array}$ & $\begin{array}{l}\text { DISPÕE SOBRE A } \\
\text { DEFINIÇÃO, } \\
\text { QUALIFICAÇÃO, } \\
\text { PRERROGATIVAS E } \\
\text { FINALIDADES DAS } \\
\text { INSTITUIÇÕES } \\
\text { COMUNITÁRIAS DE } \\
\text { EDUCAÇÃO SUPERIOR - } \\
\text { ICES, DISCIPLINA O } \\
\text { TERMO DE PARCERIA E }\end{array}$ & $\begin{array}{l}\text { Lei Ordinária } \\
12881 / 2013\end{array}$ & $\begin{array}{l}\frac{\text { http://www.planalto.gov.b }}{\mathrm{r} / \mathrm{ccivil} \text { 03/ ato2011- }} \\
\underline{\text { 2014/2013/lei/112881.htm }}\end{array}$ & $\begin{array}{l}\text { BENÉFICO } \\
\text { REGULAÇÃO } \\
\text { CONCENTRA } \\
\text { DO }\end{array}$ \\
\hline
\end{tabular}




\begin{tabular}{|c|c|c|c|c|}
\hline & $\begin{array}{l}\text { DÁ OUTRAS } \\
\text { PROVIDÊNCIAS. }\end{array}$ & & & \\
\hline $\begin{array}{l}\text { PL } \\
7522 / 2010\end{array}$ & 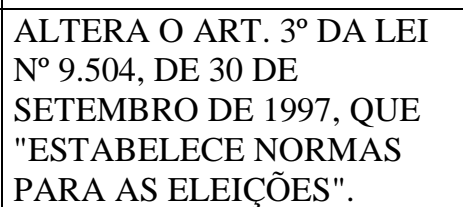 & $\begin{array}{l}\text { Lei Ordinária } \\
12.976 / 2014\end{array}$ & $\begin{array}{l}\frac{\text { http://www.planalto.gov.b }}{\mathrm{r} / \mathrm{ccivil} \text { 03/Ato2011- }} \\
\underline{\underline{\text { 2014/2014/Lei/L12976.ht }}} \\
\underline{\mathrm{m}}\end{array}$ & $\begin{array}{l}\text { NÊUTRO } \\
\text { REGULAÇÃO } \\
\text { DIFUSO }\end{array}$ \\
\hline $\begin{array}{l}\text { PL } \\
3778 / 2008\end{array}$ & $\begin{array}{l}\text { TRANSFORMA O AGRAVO } \\
\text { DE INSTRUMENTO, } \\
\text { INTERPOSTO CONTRA } \\
\text { DECISÃO QUE NÃO } \\
\text { ADMITE RECURSO } \\
\text { EXTRAORDINÁRIO OU } \\
\text { ESPECIAL, EM AGRAVO } \\
\text { NOS PRÓPRIOS AUTOS. }\end{array}$ & $\begin{array}{l}\text { Lei Ordinária } \\
12.322 / 2010\end{array}$ & $\begin{array}{l}\frac{\text { http://www.planalto.gov.b }}{\mathrm{r} / \mathrm{ccivil} \text { 03/Ato2007- }} \\
\underline{\underline{\text { 2010/2010/Lei/L12322.ht }}} \\
\underline{\mathrm{m}}\end{array}$ & $\begin{array}{l}\text { NÊUTRO } \\
\text { REGULAÇÃO } \\
\text { DIFUSO }\end{array}$ \\
\hline $\begin{array}{l}\text { PL } \\
1756 / 2007\end{array}$ & $\begin{array}{l}\text { ALTERA DISPOSITIVOS DA } \\
\text { LEI No } 4.886, \text { DE 09 DE } \\
\text { DEZEMBRO DE 1965, QUE } \\
\text { REGULA AS ATIVIDADES } \\
\text { DOS REPRESENTANTES } \\
\text { COMERCIAIS } \\
\text { AUTÔNOMOS, DISPONDO } \\
\text { SOBRE FIXAÇÃO DO } \\
\text { VALOR DAS ANUIDADES, } \\
\text { TAXAS E EMOLUMENTOS } \\
\text { DEVIDOS PELOS } \\
\text { PROFISSIONAIS DA } \\
\text { CATEGORIA, PELAS } \\
\text { PESSOAS NATURAIS E } \\
\text { JURÍDICAS, AOS } \\
\text { CONSELHOS REGIONAIS } \\
\text { DOS REPRESENTANTES } \\
\text { COMERCIAIS EM QUE } \\
\text { ESTÃO REGISTRADOS. }\end{array}$ & $\begin{array}{l}\text { Lei Ordinária } \\
12.246 / 2010\end{array}$ & $\begin{array}{l}\frac{\text { http://www.planalto.gov.b }}{\mathrm{r} / \mathrm{ccivil} \text { 03/Ato2007- }} \\
\underline{\underline{\text { 2010/2010/Lei/L12246.ht }}} \\
\underline{\mathrm{m}}\end{array}$ & $\begin{array}{l}\text { MISTO } \\
\text { REGULAÇÃO } \\
\text { CONCENTRA } \\
\text { DO }\end{array}$ \\
\hline $\begin{array}{l}\text { PL } \\
1661 / 2003\end{array}$ & $\begin{array}{l}\text { DISPÕE SOBRE O } \\
\text { DEPÓSITO JUDICIAL E } \\
\text { EXTRAJUDICIAL DE } \\
\text { VALORES REFERENTES A } \\
\text { CRÉDITOS TRIBUTÁRIOS } \\
\text { MUNICIPAIS E DÁ OUTRAS } \\
\text { PROVIDÊNCIAS. }\end{array}$ & \begin{tabular}{|l} 
Lei Ordinária \\
$10.819 / 2003$
\end{tabular} & $\frac{\frac{\text { http://www.planalto.gov.b }}{\text { r/ccivil_03/leis/2003/L10. }}}{\underline{819 . h t m}}$ & $\begin{array}{l}\text { NÊUTRO } \\
\text { REGULAÇÃO } \\
\text { DIFUSO }\end{array}$ \\
\hline PL 814/2007 & $\begin{array}{l}\text { ACRESCENTA } \\
\text { DISPOSITIVO Ã } \\
\text { CONSOLIDAÇÃO DAS LEIS } \\
\text { DO TRABALHO - CLT, } \\
\text { PARA PROIBIR O } \\
\text { TRABALHO DA GESTANTE } \\
\text { OU LACTANTE EM } \\
\text { ATIVIDADES, OPERAÇÕES } \\
\text { OU LOCAIS INSALURES. } \\
\end{array}$ & $\begin{array}{l}\text { Lei Ordinária } \\
13.287 / 2016\end{array}$ & $\begin{array}{l}\frac{\text { http://www.planalto.gov.b }}{\mathrm{r} / \mathrm{ccivil} \text { 03/_ato2015- }} \\
\underline{\text { 2018/2016/lei/L13287.ht }} \\
\underline{\mathrm{m}}\end{array}$ & $\begin{array}{l}\text { BENÉFICO } \\
\text { REGULAÇÃO } \\
\text { DIFUSO }\end{array}$ \\
\hline PL 818/2003 & $\begin{array}{l}\text { ALTERA O ART. 1.121 DA } \\
\text { LEI No } 5.869, \text { DE } 1973 \text { - } \\
\text { CÓDIGO DE PROCESSO } \\
\text { CIVIL, PARA INCLUIR, } \\
\text { COMO REQUISITO } \\
\text { INDISPENSÁVEL À } \\
\text { PETIÇÃO DE SEPARAÇÃO } \\
\text { CONSENSUAL, O ACORDO }\end{array}$ & $\begin{array}{l}\text { Lei Ordinária } \\
11.112 / 2005\end{array}$ & $\begin{array}{l}\frac{\text { http://www.planalto.gov.b }}{\text { r/ccivil 03/ ato2004- }} \\
\underline{\underline{\text { 2006/2005/lei/L11112.ht }}}\end{array}$ & $\begin{array}{l}\text { NÊUTRO } \\
\text { REGULAÇÃO } \\
\text { DIFUSO }\end{array}$ \\
\hline
\end{tabular}




\begin{tabular}{|c|c|c|c|c|}
\hline & $\begin{array}{l}\text { ENTRE OS CÔNJUGES } \\
\text { RELATIVO AO REGIME DE } \\
\text { VISITAS DOS FILHOS } \\
\text { MENORES, E DÁ OUTRAS } \\
\text { PROVIDÊNCIAS. }\end{array}$ & & & \\
\hline PLP 22/2003 & $\begin{array}{l}\text { DÁ NOVA REDAÇÃO AO } \\
\text { ART. 45 DA LEI } \\
\text { COMPLEMENTAR No 31, DE } \\
\text { 11 DE OUTUBRO DE 1977. } \\
\text { NOVA EMENTA : INSTITUI, } \\
\text { NA FORMA DO ART. 43 DA } \\
\text { CONSTITUIÇÃO FEDERAL, } \\
\text { A SUPERINTENDÊNCIA DE } \\
\text { DESENVOLVIMENTO DA } \\
\text { AMAZÔNIA - SUDAM; } \\
\text { ESTABELECE A SUA } \\
\text { COMPOSIÇÃO, NATUREZA } \\
\text { JURÍDICA, OBJETIVOS, } \\
\text { ÁREA DE COMPETÊNCIA E } \\
\text { INSTRUMENTOS DE AÇÃO; } \\
\text { DISPÕE SOBRE O FUNDO } \\
\text { DE DESENVOLVIMENTO } \\
\text { DA AMAZÔNIA - FDA; } \\
\text { ALTERA A MEDIDA } \\
\text { PROVISÓRIA No } 2.157-5, \text { DE } \\
\text { 24 DE AGOSTO DE 2001; } \\
\text { REVOGA A LEI } \\
\text { COMPLEMENTAR No 67, DE } \\
\text { 13 DE JUNHO DE 1991; E } \\
\text { DÁ OUTRAS } \\
\text { PROVIDÊNCIAS. }\end{array}$ & $\begin{array}{l}\text { Lei } \\
\text { Complementar } \\
124 / 2007\end{array}$ & $\begin{array}{l}\frac{\text { http://www.planalto.gov.b }}{\text { r/ccivil_03/leis/LCP/Lcp1 }} \\
\underline{24 . h t m}\end{array}$ & $\begin{array}{l}\text { BENÉFICO } \\
\text { T. RENDA } \\
\text { DIFUSO }\end{array}$ \\
\hline $\begin{array}{l}\text { PL } \\
1033 / 2003\end{array}$ & $\begin{array}{l}\text { INSTITUI O SALÁRIO } \\
\text { ADICIONAL DE } \\
\text { PERICULOSIDADE PARA } \\
\text { OS VIGILANTES E } \\
\text { EMPREGADOS EM } \\
\text { TRANSPORTE DE } \\
\text { VALORES. }\end{array}$ & $\begin{array}{l}\text { Lei Ordinária } \\
12.740 / 2012\end{array}$ & $\begin{array}{l}\frac{\text { http://www.planalto.gov.b }}{\text { r/ccivil_03/leis/LCP/Lcp1 }} \\
\underline{24 . h t m}\end{array}$ & $\begin{array}{l}\text { ONERANTE } \\
\text { T. RENDA } \\
\text { CONCENTRA } \\
\text { DO }\end{array}$ \\
\hline $\begin{array}{l}\text { PL } \\
7664 / 2014\end{array}$ & $\begin{array}{l}\text { ALTERA O ART. } 34 \text { DA LEI } \\
\mathrm{N}^{\circ} 9.656, \text { DE } 1998 .\end{array}$ & $\begin{array}{l}\text { Lei Ordinária } \\
13.127 / 2015\end{array}$ & $\begin{array}{l}\frac{\underline{h t t p: / / w w w . p l a n a l t o . g o v . b}}{\text { r/ccivil 03/Ato2015- }} \\
\underline{\text { 2018/2015/Lei/L13127.ht }} \\
\underline{\underline{m}} \\
\end{array}$ & $\begin{array}{l}\text { BENÉFICO } \\
\text { REGULAÇÃO } \\
\text { CONCENTRA } \\
\text { DO }\end{array}$ \\
\hline
\end{tabular}

Artigo recebido em: 2020-02-10

Artigo reapresentado em: 2020-04-28

Artigo aceito para publicação em: 2020-05-08 